\title{
Problemática asociada a la consagración de la ineficacia de las declaraciones de retención en la fuente
}

\section{Problems related to the Establisment of Retention Declarations without effects}

\author{
Adriana Paola Rincón Palacio ${ }^{1}$
}

\section{Resumen}

El presente artículo analiza problemas que trajo consigo la consagración de la ineficacia de las declaraciones de retención en la fuente presentadas sin pago total desde el punto de vista de la administración tributaria. El mecanismo, que en un principio se creyó que persuadiría a los agentes de retención para presentar sus declaraciones con pago total, terminó convirtiéndose en un obstáculo para la gestión de cobro de la administración tributaria y propició la evasión del impuesto retenido. El legislador contempló la ineficacia con el fin de acelerar el recaudo del impuesto partiendo del cumplimiento voluntario. No obstante, al parecer, olvidó que, además del cumplimiento voluntario, era necesario que la administración contara con herramientas de cobro y que, igualmente, era oportuno revisar el proceso de determinación del impuesto.

Palabras clave: Ineficacia, Procedimiento oficial de aforo, Título ejecutivo, Proceso de cobro.

\begin{abstract}
This text pretends to illustrate the reader about the main problems that were brought with the establisment of retention declarations presented without total payment, which have no effects, from the tax admin-
\end{abstract}

${ }^{1}$ Abogada de la Universidad del Norte. Especialista en Derecho Comercial de la Universidad Externado de Colombia y en Tributación de la Universidad del Norte. Magíster en Derecho del Estado con énfasis en Derecho Tributario de la Universidad Externado de Colombia. Trabaja en la División de Gestión de Cobranzas de la Dirección Seccional de Impuestos de Grandes Contribuyentes.Correos-e: Adriana.P.Rincon@gmail.com, arinconp1@dian.gov.co DOI: https://doi.org/10.18601/16926722.n13.10 
istration point of view. In the beginning, it was thought that retention agents would be persuaded to present his declarations with payment. However, it became an obstacle for collecting taxes and it also promoted tax evasion. The legislator established the declarations without effects with the purpose of acelerate collecting taxes thinking about a voluntary compliance. Although, it seems that the legislator forgot that besides voluntary compliance it was needed that the tax administration counts with collecting tools and at the same time it was an opportune moment to evaluate the tax determination procedure.

Keywords: Without effects, Tax determination procedure, Executive title, Collect process.

\section{Introducción}

La retención en la fuente es un mecanismo que permite que el recaudo del impuesto se realice en el mismo momento en que se produce el hecho generador del gravamen sobre el cual recae, ya sea el impuesto sobre la renta o el impuesto al valor agregado. En este sentido, con la retención, la administración tributaria recibe un flujo de recursos constante sin necesidad de esperar a que finalice el período gravable de cada impuesto. Se ha considerado que es una manifestación del principio de eficiencia tributaria, en la medida en que se pretende que el recaudo del tributo sea sencillo para la administración y cómodo para el contribuyente. Sin embargo, la consagración de la ineficacia de las declaraciones de retención en la fuente presentadas sin pago ha desvirtuado la eficiencia del mecanismo.
El presente artículo tiene como objetivo abordar la problemática asociada a la consagración de la ineficacia de las declaraciones de retención en la fuente, tomando como fuente primaria la experiencia adquirida de la gestión de los procesos administrativos de cobro tanto en etapa coactiva como en la de representación externa. Igualmente, se proponen las reformas legislativas y las adecuaciones internas y tecnológicas que a juicio de la autora se consideran necesarias para mejorar la eficiencia del mecanismo de recaudo.

Para efectos de determinar las razones por las cuales la consagración de la ineficacia conllevó a la ineficiencia del mecanismo de recaudo, en primer lugar, se explicará la evolución de la figura en la legislación colombiana y los mecanismos empleados a lo largo de la historia reciente para sancionar el incumplimiento en el pago de las retenciones.

Seguidamente, se analizará a fondo la problemática exponiendo las dificultades para realizar el cobro de las declaraciones de retención en la fuente ineficaces, entre las cuales se encuentra la ausencia de título ejecutivo, por cuanto se requiere de la resolución sanción por no declarar y de la liquidación oficial de aforo, lo cual demanda la gestión de varias Divisiones de Gestión de la entidad y no solamente de la División de Gestión de Cobranzas. Así mismo, se plantea el problema de la omisión en la presentación de las declaraciones como opción de planeación fiscal, el cual se agrava por la solicitud de apertura del trámite concursal de liquidación judicial. 
Por último, como se señaló anteriormente, se plantearán las soluciones que la autora estima deben implementarse para que la retención en la fuente vuelva a ser un mecanismo eficiente de recaudo de los tributos junto con las modificaciones que, a su vez, deben realizarse en el ordenamiento jurídico y las dificultades que pueden presentarse en el camino para llevar a cabo cada una de las propuestas.

Así mismo, se busca que el lector evalúe si las medidas que se pretende implementar resultarán suficientes o no para que la administración logre el recaudo de las retenciones en la fuente en el mismo período en que se llevaron a cabo las operaciones sujetas a retención.

\section{Antecedentes históricos}

En Colombia, el Artículo 99 del Decreto Extraordinario 1651 de 1961 facultó al Gobierno Nacional para establecer retenciones en la fuente con el fin de facilitar, acelerar y asegurar el recaudo del impuesto sobre la renta y sus complementarios, las cuales serán tenidas como buena cuenta o anticipo.

Posteriormente, el Artículo $2^{\circ}$ de la Ley 38 de 1969, cuyo contenido figura en el Artículo 367 del Estatuto Tributario (en adelante ET), establece que la retención en la fuente tiene por objeto conseguir en forma gradual que el impuesto se recaude en lo posible dentro del mismo ejercicio gravable en que se cause.

De esta manera, con la consagración de la retención en la fuente, la administración no tiene que esperar a que transcurran las fechas de vencimiento y pago de las declaraciones de renta para percibir el recaudo del impuesto. Por lo anterior, el mecanismo le permitió a la administración contar con un flujo constante de recursos.

Una vez establecido el mecanismo de la retención en la fuente, el legislador estableció que los pagos realizados a ciertas personas estuvieran sujetos a la retención para hacer más cómodo y sencillo el recaudo del impuesto.

En este orden de ideas, la Ley 9 de 1983, en su Artículo 47, estableció la obligación de retener a título de impuesto sobre la renta por la realización de pagos o abonos en cuenta por concepto de rentas sujetas a impuesto en Colombia, a favor de sociedades $\mathrm{u}$ otras entidades extranjeras sin domicilio en el país, personas naturales extranjeras sin residencia en Colombia y sucesiones iliquidadas de extranjeros que no eran residentes en Colombia. Así, la retención en la fuente le permitió a la administración percibir el pago del impuesto sobre la renta sobre los pagos realizados a las personas o entidades no domiciliadas en el país.

En relación con los asalariados, el Artículo 36 de la Ley 55 de 1985 elimina la declaración de renta y complementarios para los asalariados cuyos ingresos brutos provengan por lo menos en un ochenta por ciento (80\%) de pagos originados en una relación laboral o legal y reglamentaria, siempre y cuando con relación al respectivo año gravable los pagos o abonos en cuenta gravables, originados en la relación laboral o legal y reglamentaria y por otros conceptos, se les haya efectuado la retención en la fuente de que tratan las normas vigentes. A su vez, el Artículo 37 de la citada ley estableció que el impuesto de renta, patrimonio y ganancia ocasional a cargo 
de los asalariados no obligados a presentar declaración de renta y complementarios, es el que resulte de sumar las retenciones en la fuente por todo concepto, que deban aplicarse a los ingresos realizados por el contribuyente durante el respectivo año gravable. $\mathrm{Al}$ establecer la retención en la fuente para los asalariados, la administración de manera eficiente aseguró el pago de las retenciones del mayor número de contribuyentes de una manera cómoda.

La reglamentación posterior estuvo dirigida a establecer mecanismos de control de los valores retenidos por parte de la administración, teniendo en cuenta que hasta 1984 los agentes retenedores solamente tenían la obligación de consignar los valores retenidos sin necesidad de relacionarlos. Con el Decreto 81 de 1984 se exige a los retenedores la presentación ante la Administración o Recaudación de Impuestos Nacionales donde les corresponda presentar su declaración de renta, antes del primero $\left(1^{\circ}\right)$ de marzo de cada año, una relación de las retenciones efectuadas en el año inmediatamente anterior, en la cual se discriminen los apellidos y nombre o razón social o nombre tributario y NIT de la persona o entidad a quien se le practicó la retención, concepto de la misma, valor del pago o abono sujeto a retención, valor retenido y ciudad donde fue practicada junto con la relación de los recibos de pago correspondientes a las consignaciones efectuadas, acompañada de copia o fotocopia de los respectivos recibos.

Así mismo, mediante el Decreto 2503 de 1987 se exige a los agentes retenedores la presentación mensual de las declaraciones de retención en la fuente, siempre y cuando durante el período se hubieren realizado operaciones sujetas a retención.

Desde entonces ha habido distintas modificaciones de la figura, entre ellas se destacan la reforma introducida por el Artículo 11 de la Ley 1066 de 2016, con la cual las declaraciones de retención en la fuente presentadas sin pago total se tenían como no presentadas, y el Artículo 15 de la Ley 1430 de 2010, que consagró la ineficacia de las declaraciones de retención en la fuente presentadas sin pago total con el fin de procurar que el pago se hiciera de manera concomitante con la presentación de la declaración. No obstante, como veremos a continuación, no se lograron los objetivos previstos con la consagración de la ineficacia.

\section{La retención en la fuente y la sanción penal}

Para coaccionar a los agentes retenedores a la consignación de las retenciones practicadas, el legislador recurrió inicialmente a la sanción penal. En efecto, el Artículo 10 de la Ley 38 de 1969 estableció que aquellos agentes de retención que no consignaran las sumas retenidas estarían sometidos a las mismas sanciones previstas en la ley penal para los empleados públicos que incurren en peculado por apropiación. Igualmente, estableció que aquellos retenedores que declararan lo retenido por suma inferior a la real estarían sometidos a las mismas penas contempladas para el delito de falsedad.

Posteriormente, el Artículo 22 de la Ley 383 de 1997 estableció la responsabilidad penal por no consignar la retención en la fuente y el IVA consagrando un límite temporal de dos (2) meses para que el agente 
retenedor realizara la consignación de los valores retenidos. Igualmente, en dicha norma, se hizo extensiva la conducta punible a la omisión en la consignación del impuesto sobre las ventas. Así mismo, se establecieron como causales de cesación del procedimiento el pago y la compensación de las sumas adeudadas. Igualmente, se excluyeron de la sanción penal las sociedades que se encuentren en proceso concordatario o en liquidación forzosa administrativa.

Actualmente, con la Ley 599 de 2000, la conducta de omitir la consignación de las sumas retenidas dejó de ser asimilada a un peculado por apropiación para adquirir autonomía y quedar consagrada en el Artículo 402 del Código Penal como el delito de omisión de agente retenedor, el cual fue modificado por el Artículo 339 de la Ley 1819 de 2016, el cual establece lo siguiente:

ARTÍCULO 402. OMISIÓN DEL AGEN-
TE RETENEDOR O RECAUDADOR. El agente retenedor o autorretenedor que no consigne las sumas retenidas o autorretenidas por concepto de retención en la fuente dentro de los dos (2) meses siguientes a la fecha fijada por el Gobierno Nacional para la presentación y pago de la respectiva declaración de retención en la fuente o quien encargado de recaudar tasas o contribuciones públicas no las consigne dentro del término legal, incurrirá en prisión de cuarenta (48) a ciento ocho (108) meses y multa equivalente al doble de lo no consignado sin que supere el equivalente a 1.020.000 UVT.

En la misma sanción incurrirá el responsable del impuesto sobre las ventas o el impuesto nacional al consumo que, teniendo la obligación legal de hacerlo, no consigne las sumas recaudadas por dicho concepto, dentro de los dos (2) meses siguientes a la fecha fijada por el Gobierno Nacional para la presentación y pago de la respectiva declaración del impuesto sobre las ventas.

El agente retenedor o el responsable del impuesto sobre las ventas o el impuesto nacional al consumo que omita la obligación de cobrar y recaudar estos impuestos, estando obligado a ello, incurrirá en la misma pena prevista en este artículo.

Tratándose de sociedades u otras entidades, quedan sometidas a esas mismas sanciones las personas naturales encargadas en cada entidad del cumplimiento de dichas obligaciones.

PARÁGRAFO. El agente retenedor o autorretenedor, responsable del impuesto a la ventas, el impuesto nacional al consumo o el recaudador de tasas o contribuciones públicas, que extinga la obligación tributaria por pago o compensación de las sumas adeudadas, según el caso, junto con sus correspondientes intereses previstos en el Estatuto Tributario, y normas legales respectivas, se hará beneficiario de resolución inhibitoria, preclusión de investigación o cesación de procedimiento dentro del proceso penal que se hubiere iniciado por tal motivo, sin perjuicio de las sanciones administrativas a que haya lugar.

El Artículo 402 del Código Penal conserva el límite temporal de los dos (2) meses establecido en el Artículo 22 de la Ley 383 de 1997. También señala que la responsabilidad penal está en cabeza de la persona encargada del cumplimiento de las obligaciones de consignar las sumas retenidas o autorretenidas 
por concepto de retención en la fuente o las sumas recaudadas por el impuesto sobre las ventas, tal como lo estableció el Artículo 665 E.T. El pago o compensación de las sumas adeudadas junto con sus correspondientes intereses que extinga la obligación tributaria tiene el efecto de beneficiar al agente retenedor o autorretenedor con resolución inhibitoria, preclusión de investigación o cesación de procedimiento dentro del proceso penal. El Artículo 339 de la Ley 1819 de 2016 incluyó a los responsables del impuesto nacional al consumo.

La pena principal de prisión por la comisión de la conducta punible fortaleció el mecanismo de la retención en la fuente, por cuanto la libertad al igual que la vida son los bienes jurídicos más valiosos para la sociedad. Por esa razón, los contribuyentes, al ser enterados de la formulación de la denuncia penal por omisión de agente retenedor, procuran realizar el pago o presentan solicitudes de compensación para evitar a toda costa ir a prisión.

\section{El debilitamiento de la retención en la fuente a través de medidas que pretendieron que el pago se hiciera de manera concomitante con la declaración}

Así como se coaccionó penalmente a los contribuyentes para que realizaran el pago de las retenciones, el legislador acudió a medidas no punitivas para obtener la presentación y el pago de las declaraciones de retención en la fuente. En ese sentido, las Leyes 1066 de 2006 y 1430 de 2010 procuraron de manera infructuosa que los contribuyentes presentaran con pago las declaraciones de retención en la fuente.
El Artículo 11 de la Ley 1066 de 2006 adicionó un literal e) al Artículo 580 del Estatuto Tributario, estableciendo que las declaraciones de retención en la fuente presentadas sin pago se tienen por no presentadas y, así mismo, modificó el parágrafo $2^{\circ}$ del Artículo 606 del Estatuto Tributario contemplando la obligatoriedad de la presentación de la declaración de retención en la fuente, así no se hubieren realizado operaciones sujetas a retención. Sin embargo, el parágrafo $2^{\circ}$ del Artículo 20 de la Ley 1430 de 2010 eliminó la obligación de presentar la declaración de retención en la fuente cuando en el período no se hubieren llevado a cabo operaciones sujetas a retención.

Por su parte, el Artículo 15 de la Ley 1430 de 2010 modificó el Artículo 580 del Estatuto Tributario introduciendo el Artículo 580-1, el cual establece la ineficacia de las declaraciones de retención en la fuente presentadas sin pago total. Este artículo señaló que la declaración presentada sin pago no era ineficaz si el agente retenedor tenía un saldo a favor igual o superior a $82.000 \mathrm{UVT}$, generado antes de la presentación de la declaración de retención en la fuente, susceptible de compensar con el saldo a pagar de esta. Adicionalmente, el contribuyente debía presentar la solicitud de compensación dentro de los seis (6) meses siguientes a la presentación de la declaración de retención.

Ahora, con la reforma introducida por el Artículo 270 de la Ley 1819 de 2016 se permite la presentación sin pago de la declaración de retención en la fuente, siempre que el pago total de la declaración se efectúe a más tardar dentro de los dos (2) meses siguientes contados a partir de la fecha del vencimiento del plazo para declarar, sin perjuicio de la 
liquidación de los intereses moratorios a que haya lugar. En cuanto al monto del saldo a favor, la Ley 1819 de 2016 lo modificó, señalando que el saldo a favor debe ser igual o superior a dos veces el valor de la retención a cargo. No obstante, considero que el legislador debió haber contemplado que el monto del saldo a favor debe cubrir el valor de la retención más los intereses, si a ello hubiere lugar, como sucede con la compensación de las demás obligaciones fiscales, y no exigir que el saldo a favor sea igual o superior al doble del saldo a pagar, por cuanto en ocasiones puede llevarse a cabo la compensación sin la causación de intereses.

Teniendo en cuenta el plazo para pagar las declaraciones de retención en la fuente después de la reforma, podemos considerar que durante los dos (2) meses siguientes a la presentación oportuna de la declaración de retención en la fuente, la administración tributaria cuenta con un título ejecutivo.

Sin embargo, en el evento en que no se efectúe el pago de la declaración de retención dentro del término señalado anteriormente, la declaración deviene en ineficaz y se considera que el contribuyente se encuentra omiso en la presentación de la misma, por lo cual le corresponde a la administración tributaria iniciar el correspondiente procedimiento oficial de aforo. Por lo anterior, la declaración de retención en la fuente deviene en un título ejecutivo de carácter precario.

En ese sentido, con la expedición de la Ley 1819 de 2016, las declaraciones tributarias pueden clasificarse en:

1. Declaraciones válidas, las cuales prestan mérito ejecutivo.
2. Declaraciones que se tienen por no presentadas que prestan mérito ejecutivo mientras la administración no profiera el auto declarativo.

3. Declaraciones de retención en la fuente que son ineficaces si el pago de la declaración no se efectúa dentro de los dos (2) meses siguientes contados a partir del vencimiento del plazo para declarar.

Nótese entonces que respecto de estas últimas y ante la precariedad del título ejecutivo, es necesario que, en el evento en que no se paguen las declaraciones, se inicie el proceso oficial de aforo, el cual supone una mayor carga para la administración tributaria, que deberá entonces partir de la información que aparece en la declaración, pero esta será insuficiente para darle fundamento a cualquier actuación dentro del procedimiento administrativo tributario, lo cual se explicará a continuación.

\section{A. Procedimiento oficial de aforo}

Visto anteriormente que en presencia de una declaración ineficaz la administración no cuenta con un título ejecutivo, a pesar de que el agente de retención liquidó el valor de las retenciones practicadas en el período de la declaración, es necesario explicar el procedimiento que tiene que llevar a cabo la administración para finalmente obtener un título ejecutivo. Después de analizado este trámite, el lector concluirá si el mismo es sencillo o no y si debe adelantarse el mismo a pesar de la declaración.

Los doctrinantes Julio Roberto Piza Rodríguez y Olga Lucía González Parra (2010), al referirse a la liquidación de aforo dentro 
de la fiscalización y determinación tributaria, sostienen que la liquidación de aforo suple la falta de declaración, por lo cual el supuesto fáctico es una omisión predicable solo de los sujetos pasivos obligados por las normas propias de cada impuesto a presentar declaraciones tributarias. Mediante esta liquidación, el Estado en uso de las facultades de fiscalización e investigación procede a determinar oficialmente la carga tributaria del obligado, a través de la identificación de los hechos generadores, la cuantificación de la base gravable y la determinación del impuesto. En esta modalidad de liquidación oficial adquiere relevancia el correcto ejercicio de las facultades de fiscalización en cabeza de la administración de impuestos, por cuanto solamente hay lugar a adelantar el trámite para su expedición en aquellos casos donde se haya comprobado la obligación del contribuyente de declarar.

De conformidad con lo dispuesto en el Artículo 717 del Estatuto Tributario, la administración deberá adelantar este procedimiento dentro de los cinco (5) años siguientes al vencimiento del plazo señalado para declarar.

Al respecto, Álvaro Sánchez Uribe (2012), en su Tesis de Maestría en Derecho con énfasis en Tributación de la Universidad Externado de Colombia, considera que el término de cinco (5) años es bastante extenso, el cual a su juicio no se justifica en la actualidad por disponer la administración de suficientes herramientas de información. En efecto, en su trabajo de grado sostiene lo siguiente:

(...) En cuanto a lo extenso del término (cinco años contados a partir de la fecha del vencimiento del plazo para declarar) resulta justificable si nos remontamos a la época en que se origina esta disposición (decreto 2503 de 1987, incorporado al Decreto Extraordinario 624 del 30 de marzo de 1989), para la época resultaba necesario que la Administración Tributaria estuviera dotada de un término tan amplio dado que no existían sistemas informáticos, ni la regulación actual en materia de información exógena y otras técnicas modernas de revisión, hecho que hacía complejo que en la etapa de investigación se pudiera obtener de manera expedita y con la mayor cobertura posible la información que permitiera probar los factores y bases necesarias para determinar oficiosamente el impuesto de quien no declaraba. En la Grafica No 1, se ilustra lo prolongado que resulta en el tiempo, el término para proferir esta actuación (La Liquidación Oficial de Aforo), que finalmente se constituye en el titulo objeto de cobro y que por efecto de este término resulta evidente que le genera complejidad a la Administración Tributaria, para ejercer eficientemente el cobro de la obligación, para lo cual tiene un tiempo adicional de cinco (5) años, tal como lo contempla el artículo 817 del E.T., ello sin considerar el termino de interrupción y suspensión establecido en el artículo 818 del E.T., no solo por el valor que resulte a cargo del obligado (impuestos más intereses, adicionando a ello la sanción por no declarar), si no lo complejo que podría resultar la ubicación del contribuyente que no declaró. En la actualidad la Administración Tributaria, las demás entidades públicas y privadas y los contribuyentes en general, han tenido evidentes avances en materia informática que le permiten, junto con disposiciones de control como la información exógena, el intercambio de datos con fines de fiscalización y control que 
permiten conocer las operaciones, así como los ingresos y bienes de quienes infringen las disposiciones tributarias, es por ello, que independientemente del término que actualmente se tiene para preferir esta liquidación oficial que es de cinco (5) años, se tienen mayores y mejores herramientas de control para mejorar la eficiencia al exigir este tipo de obligación, lo que haría pensar y evaluar en una modificación normativa, la reducción sustancial de este término, para mejorar la eficiencia de la Administración Tributaria en este sentido (...).

Por su parte, la administración tributaria considera que se justifica mantener el término de cinco (5) años, por cuanto les permite a los funcionarios de las Divisiones de Gestión de Fiscalización adelantar la investigación de otros procesos con términos próximos a vencerse. Sin embargo, se ha comprobado que si la administración demora el inicio de los procesos de determinación, cuando comience las investigaciones puede tener inconvenientes como las dificultades para ubicar al deudor o la insolvencia de este.

De lo anteriormente expuesto se concluye que el primer problema del proceso de determinación, que influye en la constitución del título ejecutivo base de cobro de las retenciones en la fuente ineficaces, es el término para adelantar el proceso de aforo, el cual puede considerarse extenso teniendo en cuenta la información disponible por parte de la administración tributaria.

Dentro del procedimiento oficial de aforo, al presunto obligado omiso se le garantiza su derecho al debido proceso y a la defensa en la medida en que puede oponerse al emplazamiento para declarar por medio de un memorial en el cual exponga los motivos jurídicos y fácticos que acrediten, ya sea que la obligación se cumplió o que la misma nunca surgió, o proceda a cumplir con la obligación omitida, presentando la respectiva declaración, pagando el impuesto a cargo, los intereses moratorios a que hubiera lugar y la correspondiente sanción por extemporaneidad, de conformidad con el Artículo 642 del Estatuto Tributario (Cermeño, César; De Bedout, Juan; García, Sonia y Clopatofsky, Carlos, 2016). Adicionalmente, puede interponer recurso de reconsideración contra la resolución sanción por no declarar, y contra la liquidación oficial de aforo.

Una vez resuelto el recurso de reconsideración de manera desfavorable para el contribuyente, este podrá formular demanda de nulidad y restablecimiento contra la resolución que impone la sanción por no declarar y contra la liquidación oficial de aforo dentro de los cuatro (4) meses siguientes contados a partir de la notificación de cada uno de los actos administrativos anteriormente mencionados.

Si el contribuyente no hubiere interpuesto los recursos por la vía gubernativa, es procedente la revocatoria directa prevista en los Artículos 93 al 97 de la Ley 1437 de 2011 (CPACA). El término para ejercitar la revocatoria directa será de dos (2) años a partir de la ejecutoria del correspondiente acto administrativo. Por su parte, la administración deberá fallar las solicitudes de revocatoria directa dentro del término de un (1) año contado a partir de su petición en debida forma.

Hasta tanto no culmine el proceso de determinación con un acto administrativo ejecutoriado, el cual puede demorarse más de 
cinco (5) años por la demora de la jurisdicción de lo contencioso administrativo en resolver en forma definitiva las acciones de nulidad y restablecimiento del derecho, la administración tributaria no cuenta con un título ejecutivo para hacer el cobro de la declaración ineficaz, ni tampoco puede proceder a la práctica de medidas cautelares que garanticen el pago de las declaraciones. Estos problemas serán expuestos a continuación, junto con las correspondientes soluciones.

\section{Principales problemas asociados a la consagración de la ineficacia de las declaraciones de retención en la fuente presentadas sin pago total}

\section{A. Fomento de la evasión tributaria}

La consagración de la ineficacia de las declaraciones de retención en la fuente presentadas sin pago total, en lugar de propender a la presentación oportuna con pago total de las declaraciones de retención en la fuente, ha propiciado la no presentación de dichas declaraciones tributarias por parte de los contribuyentes.

En efecto, en nuestro sistema tributario, la autoliquidación es el sistema en torno al cual se estructura la actuación de la administración tributaria para hacer efectivo el pago del impuesto. Sin embargo, como lo señala Julio Roberto Piza ${ }^{2}$, "este esquema de gestión tributaria entraña un riesgo latente: que los contribuyentes, abusando de su posición, incumplan con sus obligaciones tributarias, bien sea mediante conductas evasivas -las cuales implican la ocultación de datos relativos a hechos imponibles cuya plena realización ya ha tenido lugar-, o mediante conductas elusivas, siendo estas más difíciles de detectar y combatir para la administración porque su adecuada comprensión implica un grado de sofisticación nunca exento de debate, a pesar de que todos creen entender de qué se trata".

Con el establecimiento de la ineficacia de las declaraciones de retención en la fuente, algunos contribuyentes han seguido apropiándose de los dineros públicos sin trasladarlos a la administración tributaria, sin ningún temor a ser fiscalizados por la omisión en la presentación de las declaraciones, aprovechando que los controles extensivos ${ }^{3}$ no son eficientes, por las siguientes razones:

a) La selección del universo de los contribuyentes a fiscalizar se hace con base en los programas de fiscalización o en las solicitudes de investigación realizadas por las diferentes dependencias de las Direcciones Seccionales o en las

${ }^{2}$ PIZA, J. (2014). La función de fiscalización tributaria en Colombia. Recuperado el 1 de junio de 2016 de revistas.uexternado.edu.co/index.php/fiscal/article/download/3934/4227.

${ }^{3}$ De acuerdo con Quevedo (2014), los controles extensivos han sido definidos como "aquellas acciones de control que realiza la Administración Tributaria a una gran cantidad de contribuyentes, de manera simultánea o en un lapso de tiempo relativamente corto, con el propósito de asegurar el cumplimiento tributario, o detectar el incumplimiento tributario a fin de aplicar las medidas correctivas que correspondan". Publicado en: Eficiencia en los controles extensivos. Recuperado el 1 de junio de 2016 de www.ief.es/documentos/recursos/publicaciones/revistas/ cuadernos.../2014_18_20.pdf. 
denuncias de terceros. Sin embargo, se han detectado casos de contribuyentes que han dejado de presentar sus declaraciones durante un período de tiempo prolongado y no han sido fiscalizados por no haber sido seleccionados.

b)Los controles extensivos no se han realizado durante un periodo corto de tiempo contado a partir del incumplimiento de los deberes formales.

Teniendo en cuenta que la Ley le concede a la administración tributaria un término de cinco (5) años para proferir la liquidación oficial de aforo, generalmente, la administración tributaria dedica los dos (2) primeros años para atender otras investigaciones pendientes y solamente a partir del tercer (3) año empieza a realizar los controles extensivos. Para los contribuyentes que no han sido admitidos a un proceso de insolvencia, no se presenta ningún inconveniente al realizar los controles a partir del tercer (3) año, pero para aquellos que durante el transcurso de los tres (3) años han sido admitidos a un trámite concursal de reorganización o liquidación, el ejercicio de los controles resulta tardío, por cuanto hay muy pocas probabilidades de que los contribuyentes en un trámite de insolvencia cumplan con el pago de la obligación que finalmente resulte determinada, si no se presentan inconvenientes en el proceso oficial de aforo como la no ubicación del contribuyente.

Además, debe tenerse en cuenta que, en Colombia, pese a la coyuntura de la baja en los precios del petróleo, algunas compañías del sector petrolero no fueron seleccionadas en los programas de fiscalización, y cuando se solicitó la investigación por el incumplimiento en la declaración y pago de las retenciones en la fuente fue muy tarde, por cuanto ya habían sido admitidas a los trámites de reorganización o liquidación judicial.

También se han detectado casos de empresas que han persistido en el incumplimiento en la presentación y pago de las declaraciones de retención en la fuente y no han sido seleccionadas por los programas de fiscalización.

\section{B. Ausencia de título ejecutivo}

El Artículo 422 del Código General del Proceso establece que pueden demandarse ejecutivamente las obligaciones expresas, claras y exigibles que consten en documentos que provengan del deudor o de su causante, y constituyan plena prueba contra él, o las que emanen de una sentencia de condena proferida por juez o tribunal de cualquier jurisdicción, o de otra providencia judicial, o de las providencias que en procesos de policía aprueben liquidación de costas o señalen honorarios de auxiliares de la justicia, y los demás documentos que señale la ley.

En el ámbito tributario, el Artículo 828 del Estatuto Tributario señala taxativamente los documentos que prestan mérito ejecutivo, indicando que dentro de los mismos se encuentran las liquidaciones privadas y sus correcciones, contenidas en las declaraciones tributarias presentadas desde el vencimiento de la fecha para su cancelación. Sin embargo, para que las liquidaciones privadas contenidas en las declaraciones tributarias presten mérito ejecutivo, se requiere, además de que contengan obligaciones expresas, 
claras y exigibles, que las declaraciones sean eficaces ${ }^{4}$. Por lo tanto, las declaraciones de retención en la fuente presentadas sin pago total, que son ineficaces, sin necesidad de acto administrativo que así lo declare, no prestan mérito ejecutivo, por cuanto al no producir efecto legal alguno, también se les cercenó su fuerza ejecutiva. Si se llegare a librar mandamiento de pago con base en una declaración ineficaz, el ejecutado podría proponer la excepción de falta de título ejecutivo, contemplada en el numeral $7^{\circ} \mathrm{del}$ Artículo 831 del Estatuto Tributario, la cual está llamada a prosperar 5 .

Por lo anterior, ante la presencia de una declaración de retención en la fuente presentada sin pago total, es necesario que la División de Gestión de Fiscalización inicie el proceso de determinación del impuesto e imposición de sanciones previo al cobro de los valores determinados por la Administración Tributaria.

Ahora bien, con la Ley 1819 de 2016 se les otorgó a los contribuyentes un plazo de dos (2) meses para el pago de sus retenciones en la fuente. Sin embargo, ese término es insuficiente para iniciar el proceso administrativo de cobro. Si se inicia el proceso administrativo de cobro, la administración tributaria se expone a que dentro del trámite la declaración deje de ser exigible y se torne ineficaz.

Otro problema que se deriva de la ausencia de título ejecutivo es la imposibilidad de hacer efectiva la responsabilidad subsidiaria contra los representantes legales, que está contemplada en los Artículos 573 y 798 del Estatuto Tributario, los cuales establecen que los obligados al cumplimiento de deberes formales de terceros responden subsidiariamente cuando omitan cumplir tales deberes, por las consecuencias que se deriven de su omisión.

Sobre la responsabilidad subsidiaria, la Dirección de Impuestos y Aduanas Nacionales, mediante el Concepto No. 40423 del 14 de julio de 2003, sostuvo lo siguiente:

(...) En cambio, la responsabilidad subsidiaria como su nombre lo indica, aunque esté previamente determinada en la Ley, solo opera de manera residual, al cumplimiento de una condición, que es la de que el deudor principal no pague. En el Diccionario de Derecho Usual de Guillermo Cabanellas, Quinta Edición, Ediciones Santillana, se de-

\footnotetext{
${ }^{4} \mathrm{Al}$ respecto, los autores César Camilo Cermeño, Juan Camilo de Bedout, Sonia García y Carlos Mario Clopatofsky (2016) sostienen que teniendo en cuenta que el alcance del título ejecutivo prevé la existencia de una obligación clara, expresa y exigible, es determinante analizar la validez efectiva de la declaración tributaria, ya que en caso de que se configure alguna de las causales de ineficacia consagradas en forma expresa en la ley, la misma no podría ser tenida en cuenta como título ejecutivo para fundamentar el proceso de cobro coactivo, y al no existir un título ejecutivo, consecuencialmente no subsistirá una obligación clara, expresa y exigible.

${ }^{5}$ El Consejo de Estado, mediante Sentencia del 20 de agosto de 2009, proferida dentro del expediente 16038, declaró probada la excepción de falta de título ejecutivo y ordenó la terminación y archivo del proceso coactivo adelantado para el cobro de una declaración presentada por una persona no obligada a declarar, la cual, conforme a lo dispuesto en el Artículo 594-2 del Estatuto Tributario, no produce efecto legal alguno.
} 
fine la Responsabilidad Subsidiaria como: "La escalonada, de modo tal que la insolvencia o incumplimiento de una persona o de una clase de responsables, determina la posibilidad de dirigirse contra otra, a fin de exigir la responsabilidad que no ha resultado factible satisfacer en todo o en parte por los principales obligados". . "Significa lo anterior, que no puede iniciarse proceso de cobro contra el deudor subsidiario, sino cuando esté demostrado en la actuación, que la labor de cobro en contra del deudor principal ha sido fallida (...).

De lo anteriormente expuesto se concluye que, pese a que los Artículos 573 y 798 del Estatuto Tributario establecen la responsabilidad subsidiaria de los administradores, representantes legales y revisores fiscales que firmaron las declaraciones, tratándose de las declaraciones ineficaces, la administración tributaria no puede dirigirse contra ellos, pese a contar con un documento dotado de presunción de veracidad, por cuanto debe dirigirse primero contra la entidad retenedora. Sin embargo, no puede realizarse el cobro contra el retenedor, ya que las declaraciones no prestan mérito ejecutivo.

\section{Imposibilidad de practicar medidas cautelares para el cobro de los valores de- clarados en las declaraciones ineficaces}

La Corte Constitucional ${ }^{6}$ ha señalado la importancia de las medidas cautelares, en los siguientes términos:
En nuestro régimen jurídico, las medidas cautelares están concebidas como un instrumento jurídico que tiene por objeto garantizar el ejercicio de un derecho objetivo, legal o convencionalmente reconocido (por ejemplo el cobro ejecutivo de créditos), impedir que se modifique una situación de hecho o de derecho (secuestro preventivo en sucesiones) o asegurar los resultados de una decisión judicial o administrativa futura, mientras se adelanta y concluye la actuación respectiva, situaciones que de otra forma quedarían desprotegidas ante la no improbable actividad o conducta maliciosa del actual o eventual obligado.

Las medidas cautelares a veces asumen el carácter de verdaderos procesos autónomos (v. gr. separación de bienes, protección policiva a la posesión de hecho, etc.), cuando ellas constituyen precisamente la finalidad o el objetivo del mismo. Pero también, y esta es la generalidad de los casos, dichas medidas son dependientes o accesorias a un proceso cuando su aplicación y vigencia está condicionada a la existencia de este, como ocurre en los casos del proceso ejecutivo, o en materia penal con el embargo y secuestro de bienes del imputado (C.P.P. art. 52).

Igualmente, las medidas cautelares son también provisionales o contingentes, en la medida en que son susceptibles de modificarse o suprimirse a voluntad del beneficiado con ellas o por el ofrecimiento de una contragarantía por el sujeto afectado y, desde 
luego, cuando el derecho en discusión no se materializa. Naturalmente, las medidas se mantienen mientras persistan las situaciones de hecho o de derecho que dieron lugar a su expedición.

Si bien la ocurrencia de una situación de hecho o de derecho determina el ejercicio de la medida cautelar, cabe advertir que la razón de ser de esta no está necesariamente sustentada sobre la validez de la situación que la justifica. De manera que el título de recaudo, por ejemplo, puede ser cuestionable y esa circunstancia no influye sobre la viabilidad procesal de la cautela si se decretó con arreglo a la norma que la autoriza. Es por esta circunstancia particular que no puede aducirse que la cautela siempre conduzca a violentar o desconocer los derechos del sujeto afectado con la medida. Obviamente, cuando la medida de cautela es ilegal puede ocasionarse perjuicios, cuyo resarcimiento es posible demandar por el afectado.

De acuerdo con lo antes expuesto, se concluye que para la Corte Constitucional las medidas cautelares tienen por objeto garantizar el cobro ejecutivo de créditos, impedir que se modifique una situación de hecho o de derecho o asegurar los resultados de una decisión judicial o administrativa futura.

Para la práctica de las medidas cautelares, requiere que previamente la administración tributaria tenga un título ejecutivo, en el cual conste una obligación clara, expresa y actualmente exigible. Las medidas cautelares que se practican en los procesos administrativos son el embargo y secuestro de bienes del deudor.

El embargo de saldos bancarios y de créditos son mecanismos efectivos para obtener el pago de las obligaciones tributarias, en la medida en que le permiten a la administración tener títulos de depósito judicial ${ }^{7}$ que pueden ser aplicados directamente al pago de las obligaciones, sin necesidad de agotar el procedimiento de secuestro, avalúo y remate que debe surtirse en caso del embargo de bienes inmuebles.

Sin embargo, en el caso de las declaraciones de retención en la fuente presentadas sin pago total, al ser ineficaces de pleno derecho, esto es, al no ostentar el carácter de título ejecutivo, no se podría ordenar la práctica de las medidas cautelares de embargo y secuestro para garantizar el pago de estas.

Por lo anterior, tenemos que si bien con la consagración de la ineficacia se pretendió que el agente de retención presentara y pagara voluntariamente las declaraciones de retención en la fuente dentro de los plazos previstos en la Ley, lo cierto es que dicha medida implicó sustraerle a la administración una de las herramientas más efectivas para

\footnotetext{
${ }^{7}$ De acuerdo con la Coordinación de Escuela de Impuestos y Aduanas Nacionales (2016), los títulos de depósito judicial son los documentos soporte de los dineros consignados a nombre de la Dirección Nacional de Impuestos y Aduanas Nacionales DIAN, como producto de una medida cautelar de embargo a sumas de dinero, remate de bienes, o puestos a disposición por otra entidad del Estado en virtud de la prelación de créditos o embargo de remanentes.
} 
realizar el cobro, que consiste en la práctica de medidas cautelares. Para la práctica de medidas cautelares, la administración tributaria tiene que finalizar el largo proceso de determinación. Al finalizar el proceso, la administración puede encontrar que no existen bienes o créditos para embargar y secuestrar del agente retenedor, que garanticen el pago de la obligación, por encontrarse en liquidación voluntaria o haber sido admitido el trámite de liquidación judicial.

\section{Imposibilidad de obtener el pago total de las retenciones en la fuente en el trá- mite de liquidación judicial}

El literal g) del Artículo 49 de la Ley 1116 de 2006 contempla dentro de las causales de liquidación judicial inmediata el "tener a cargo obligaciones vencidas, por concepto de mesadas pensionales, retenciones de carácter obligatorio a favor de autoridades fiscales, descuentos efectuados a los trabajadores, o aportes al Sistema de Seguridad Social Integral, sin que las mismas fuesen subsanadas dentro del término indicado por el Juez del concurso, que en ningún caso será superior a tres (3) meses".

Sin embargo, se ha demostrado que, en ocasiones, la Superintendencia de Sociedades demora la apertura del trámite de liquidación judicial, lo cual implica que se aumente para la administración el pasivo por con- cepto de retenciones en la fuente, el cual se manifiesta en la omisión en la presentación de las declaraciones o la presentación sin pago (ineficacia). Lo más grave es que pese a la demora que se pueda registrar, es muy poco probable que la administración haya culminado un procedimiento oficial de aforo antes de la apertura del trámite concursal de liquidación judicial.

Una vez declarada la apertura del trámite de liquidación judicial y realizada la publicación del aviso que informa a los acreedores sobre el concurso, los acreedores cuentan con un plazo de veinte (20) días para presentar su crédito al liquidador, allegando prueba de la existencia y cuantía de este.

En cuanto a la prueba de la existencia y cuantía del crédito, tratándose de las declaraciones de retención en la fuente presentadas sin pago, el funcionario de la administración tributaria debe allegar copias de las declaraciones y presentarlas como créditos contingentes ${ }^{8}$. Si el agente de retención no presentó las declaraciones, es necesario que allegue las resoluciones por medio de las cuales se le impone sanción por no declarar o las liquidaciones oficiales de aforo. En caso de que las declaraciones de retención en la fuente se encuentren en etapa de investigación, debe allegarse al trámite concursal copias de los autos de apertura de las investigaciones o de los emplazamientos para declarar y deberán

\footnotetext{
${ }^{8}$ Según Gabriel A. García Escobar, los créditos contingentes son los sometidos a condición suspensiva, los litigiosos y los créditos de Derecho público de las Administraciones Públicas, que resulten de procedimientos de comprobación o inspección (hasta su cuantificación). (El tratamiento de los créditos concursales y el principio par conditio creditorum. Publicado en Revista Internacional de Doctrina y Jurisprudencia. Disponible en https://w3.ual.es/revistas/.../pdfs/2014-03/articulos_eltratamiento-de-los-creditos.pdf.
} 
presentarse como obligaciones contingentes en cuantía indeterminada.

En el evento en que la obligación por concepto de retención en la fuente se hubiere causado, pero a la fecha de apertura de la liquidación no sea exigible aún por no haber transcurrido el vencimiento del plazo para declarar, la administración tributaria deberá presentarla como crédito contingente de la liquidación. En este último evento, surge un problema para la administración, en la medida en que si la declaración no es presentada, resulta complicado para ella aportar copia de la declaración y presentarla como obligación contingente, pues no existe prueba de la existencia del crédito ni de su cuantía. Sin embargo, el funcionario de Cobranzas debe presentarla como obligación contingente en cuantía indeterminada.

Al respecto, el Artículo 25 de la Ley 1116 de 2006 establece que en el memorial de presentación de créditos deben relacionarse todas las acreencias causadas u originadas con anterioridad a la fecha de inicio del proceso, discriminando la cuantía del capital. Por lo anterior, la Superintendencia de Sociedades tiene en cuenta la causación y no la exigibilidad de las obligaciones para efectos de la presentación de los créditos. Sin embargo, en el momento de redactar la norma, no se tuvo en cuenta que es a partir de la exigibilidad de la obligación cuando la administración tributaria puede conocer la cuantía de las retenciones practicadas y no antes.

Después de presentados los créditos, el liquidador debe allegar un proyecto de calificación y graduación de créditos y derechos de voto, en el cual estén detalladas claramente las obligaciones y los acreedores de estas, debidamente clasificados para el caso de los créditos, en los términos del Título XL del Libro Cuarto del Código Civil y demás normas legales que lo modifiquen o adicionen.

Tratándose de acreencias ciertas, esto es, cuando estamos en presencia de una resolución sanción por no declarar o una liquidación oficial de aforo, los créditos fiscales deben graduarse dentro del quinto orden de los créditos de primera clase después de los créditos por concepto de mesadas pensionales, de los créditos laborales, de los créditos por alimentos a favor de menores y de los créditos a favor de sociedades administradoras de fondos de pensiones y cesantías, por concepto de aportes. Si se trata de obligaciones contingentes, se gradúa dentro de los créditos condicionales o litigiosos.

Respecto al reconocimiento de las obligaciones contingentes, la Superintentencia de Sociedades, en el acta de la audiencia de resolución de objeciones llevada a cabo el 30 de octubre de 2015 dentro del trámite de liquidación judicial de la sociedad Sismografía y Petróleos de Colombia S.A.S. Expediente: 39.695, precisó que para reconocer una obligación contingente dentro del trámite concursal se requiere que la cuantía de la misma esté determinada en los siguientes términos:

(...) De acuerdo con el Artículo 48.5 de la Ley 1116 de 2006, mencionado reiteradamente, solamente pueden reconocerse los créditos respecto de los que conste prueba de la existencia y cuantía.

De esta forma, como un crédito cierto únicamente es posible reconocer la suma acreditada con las declaraciones, esto 
es $\$ 13.028 .452 .000$ de capital en primera clase fiscal e intereses postergados por $\$ 2.032 .045 .000$. Contrario a lo afirmado por el liquidador, el crédito de capital sí debe incluir la sanción ya que es de carácter legal y no convencional y por lo tanto no debe ser postergada en los términos del artículo 69.4 del régimen de insolvencia.

Respecto de los demás créditos reclamados en la objeción, vale la pena advertir que cuando se omite la presentación de una declaración tributaria, como en el caso planteado, la DIAN puede emplazar al obligado para que cumpla con dicho deber en los términos de ley, sin que en este caso se observe una actuación de la autoridad tributaria, para que la sociedad declare y pague los impuestos presuntamente omitidos.

Si bien por definición no puede establecerse la cuantía de un crédito contingente, a esta fecha, por vía de liquidación de aforo, la administración tributaria ya debería tener determinados los impuestos, sanciones e intereses pendientes por pagar y a cargo de la sociedad en insolvencia que solicita sean graduados. Por esta razón se reconocerán y graduarán las sumas contingentes, pero se requerirá al citado acreedor, para que con la colaboración del liquidador como representante legal de la compañía, determine y presente la cuantía y naturaleza de los contingentes a que hace referencia en su crédito en el término improrrogable de dos (2) meses, contados a partir de la celebración de esta audiencia. En caso de incumplir el plazo anotado, el crédito será rechazado. De esta forma, el crédito contingente será de cuantía indeterminada, aunque la administración tributaria lo estima en la suma de $\$ 8.630 .465 .750(\ldots)$.
En ese sentido, la Superintendencia de Sociedades considera que, si bien los créditos contingentes pueden presentarse en cuantía indeterminada cuando el contribuyente omite la presentación de las declaraciones tributarias, la administración tributaria debe tener determinados los impuestos, sanciones e intereses que solicita que le sean graduados hasta antes de que se adjudiquen los bienes inventariados. De lo contrario, los créditos contingentes inicialmente reconocidos en cuantía indeterminada serán rechazados.

Ahora, si bien el inciso $2^{\circ}$ del Artículo 25 de la Ley 1116 de 2006 establece que los créditos litigiosos y las acreencias condicionales quedarán sujetos a los términos previstos en el acuerdo en condiciones iguales a los de su misma clase y prelación legal, así como a las resultas correspondientes al cumplimiento de la condición o de la sentencia o laudo respectivo y, en el entretanto, el deudor constituirá una provisión contable para atender su pago, dicha provisión la constituye sobre acreencias que estén determinadas.

De otra parte, de acuerdo con lo señalado en el apartado correspondiente al procedimiento oficial de aforo, se observa que el término con que cuenta la administración para desplegar las actuaciones tendientes a proferir liquidación de aforo y/o resolución sanción por no declarar para determinar los impuestos, sanciones e intereses, en el caso de que el agente retenedor no hubiere presentado las declaraciones de retención en la fuente y sea admitido a un trámite de liquidación judicial, resulta muy corto en la medida en que el procedimiento de aforo demora mucho más de dos (2) meses. Lo anterior significa que los términos del procedimiento 
de aforo no concuerdan con los términos del trámite de liquidación judicial.

En efecto, la Superintendencia de Sociedades, mediante el Oficio No. 220-005655 del 27 de enero de 2014, ha precisado que el proceso de liquidación judicial dura aproximadamente ocho (8) meses, si no se presentan circunstancias o hechos que dilaten en el tiempo su culminación, tales como recursos, nulidades, incidentes, etc., lo cual tiene su respaldo en la información que se relaciona a continuación, la cual fue tomada de la página web de la Superintendencia de Sociedades:

\section{Duración promedio de los procesos de liquidación judicial}

\begin{tabular}{|c|c|c|c|}
\hline $\begin{array}{c}\text { Estado del } \\
\text { proceso }\end{array}$ & $\begin{array}{c}\text { Número de } \\
\text { personas } \\
\text { naturales o } \\
\text { jurídicas }\end{array}$ & $\begin{array}{c}\text { Dura- } \\
\text { ción pro- } \\
\text { medio en } \\
\text { días }\end{array}$ & $\begin{array}{c}\text { Dura- } \\
\text { ción pro- } \\
\text { medio en } \\
\text { años }\end{array}$ \\
\hline En trámite* & 211 & 484 & 1,33 \\
\hline Terminado** & 318 & 535 & 1.47 \\
\hline
\end{tabular}

Fuente: SIGS (Módulo de Procesos).

* Desde la fecha de aceptación hasta la fecha del acumulado. ** Desde la fecha de aceptación al proceso hasta la fecha de terminación del mismo.

Durante los términos anteriores, es poco probable que la administración haya culminado el procedimiento oficial de aforo.

Continuando con el trámite de liquidación judicial tenemos que, una vez resueltas las objeciones contra el proyecto de graduación y calificación de créditos, el liquidador cuenta con un término de dos (2) meses para enajenar los activos inventariados. Con relación a los dineros recibidos y los activos no enajenados, el liquidador tendrá un plazo máximo de treinta (30) días para presentar al juez del concurso el acuerdo de adjudicación al que hayan llegado los acreedores del deudor.

En esta etapa se requiere que las obligaciones con carácter contingente se encuentren determinadas, por cuanto el liquidador no puede proceder a realizar adjudicaciones de las cuales se desconozca la cuantía de la deuda. De la misma manera, no puede proceder a realizar adjudicaciones sobre obligaciones que no sean exigibles. Por lo anterior, si no se ha proferido resolución sanción por no declarar o liquidación oficial de aforo, lo más probable es que la sociedad en trámite de insolvencia no pague suma alguna por concepto de retención en la fuente, si no realizó la presentación de la declaración.

En cuanto a las declaraciones ineficaces, los liquidadores de las empresas en insolvencia en algunos casos las han reconocido en el proyecto de graduación y calificación de créditos como obligaciones ciertas. Sin embargo, si el pago de estas no se hace de manera concurrente con la declaración, siguen siendo ineficaces. Al respecto, la DIAN, en el Concepto No. 000496 del 31 de mayo de 2016, sostuvo lo siguiente:

(...) Ahora bien, obsérvese que la Ley 1116 de 2006 claramente establece que los créditos a favor de la DIAN en lo que hace referencia a las "condiciones de pago y las tasas", no se aplicarán las reglas del Estatuto Tributario sino que deberán observar lo establecido en el acuerdo de reorganización o de adjudicación, dejando incólume las demás disposiciones reguladas en la normativa tributaria, entre ellas y para el caso 
objeto de análisis, lo regulado en el artículo 580-1 del Estatuto Tributario.

El hecho que la norma de insolvencia impida el pago por parte del liquidador o representante legal hasta tanto el mismo sea aprobado, no implica una autorización tacita para que los agentes retenedores se eximan de presentar con pago su declaración de retención en la fuente dentro de los plazos establecidos por la Administración Tributaria. Ello se justifica, toda vez que como bien lo señaló el legislador en la exposición de motivos de la Ley 1430 de 2010 las sumas retenidas constituyen valores de propiedad del fisco nacional "desde el momento mismo en que se práctica la retención en la fuente".

En este sentido, y de acuerdo con la hipótesis planteada en su consulta "las declaraciones de retención en la fuente presentadas con anterioridad o con posterioridad del proceso concursal sin pago o con pago parcial" devienen como ineficaces de pleno derecho, lo que implica que no producen efecto legal alguno en los términos del artículo 580-1 del E.T. Esta consecuencia, es plausible toda vez que nos encontramos ante el incumplimiento por parte del agente retenedor de su obligación de trasladar las sumas retenidas, con lo que se estaría incumpliendo con los objetivos de este mecanismo como son el de facilitar, acelerar y garantizar el recaudo de forma eficiente, controlando la evasión de impuestos.

Igualmente, debe tenerse en cuenta que, de conformidad con lo dispuesto en el numeral $6^{\circ}$ del Artículo 69 de la Ley 1116 de
2016, el valor de los intereses es un crédito legalmente postergado dentro del proceso de liquidación judicial, por lo que si la sociedad concursada realiza el pago de las declaraciones sin el pago de los intereses, no se entiende subsanada la ineficacia.

\section{E. Injusta imposición de la sanción por extemporaneidad en las declaraciones ineficaces presentadas oportunamente, pero cuyo pago se realiza después de los dos (2) meses siguientes al vencimiento del plazo para declarar}

El inciso $4^{\circ}$ del Artículo 580-1 E.T. establece que la declaración de retención en la fuente que se haya presentado sin pago total antes del vencimiento del plazo para declarar u oportunamente, producirá efectos legales, siempre y cuando el pago total de la retención se efectúe o se haya efectuado a más tardar dentro de los dos (2) meses siguientes contados a partir del plazo para declarar, sin perjuicio de la liquidación de los intereses moratorios a que haya lugar. Lo anterior significa que, si el agente de retención presenta oportunamente la declaración de retención en la fuente, pero no realiza el pago dentro de los dos (2) meses siguientes, la declaración presentada pasa de ser válida a ser ineficaz, por lo cual deberá presentarla nuevamente con el pago de la sanción por extemporaneidad, lo cual desconoce la presentación oportuna que se realizó inicialmente.

Adicionalmente, debe tenerse en cuenta que los Artículos 641 y 642 E.T. sancionan la presentación de la declaración por fuera de los plazos de vencimiento para declarar, sin que sancionen el pago extemporáneo, por 
cuanto la extemporaneidad en el pago genera intereses moratorios ${ }^{9}$.

Por lo anterior, al exigirle al agente retenedor el pago de la sanción por extemporaneidad por haber realizado el pago por fuera del término legal junto con el pago de intereses moratorios torna más gravosa su situación.

Sobre la sanción por extemporaneidad, Piza (2010) sostiene que sancionar como infracción el simple retraso en el cumplimiento, incluso cuando posteriormente se presenta la declaración de forma espontánea, sin mediar requerimiento previo de la Administración, resulta excesivo y ajeno a la idea de proporcionalidad en la reacción represiva que es uno de los principios inspiradores del ordenamiento sancionador. Por lo anterior, considera que lo que en realidad establecen los Artículos 641 y 642 E.T. son figuras que atienden al concepto de recargos ${ }^{10}$, porque su finalidad no es preventivo-represiva, sino que está orientada a constreñir al sujeto a la realización del comportamiento omitido, circunstancia que se ve confirmada por el hecho de que las normas introducen una diferenciación entre las diversas formas de cumplimiento extemporáneo: con y sin actuación administrativa.

No obstante, tratándose de declaraciones de retención en la fuente presentadas oportunamente, pero con pago realizado por fuera del término de dos (2) meses, no se está imponiendo un recargo por declaración extemporánea, sino por pago extemporáneo, lo cual no tiene respaldo en la legislación colombiana ni en la legislación extranjera.

\section{F. Improcedencia de la solicitud de facili- dad de pago por retenciones en la fuente pese a la existencia de norma legal que lo permite}

De acuerdo con Cecilia Rico (2011), la facilidad de pago como mecanismo de recaudo tiene como ventaja principal la recuperación del crédito fiscal sin obstaculizar la actividad económica del contribuyente deudor, facilitando la permanencia en el mercado de empresas que eventualmente desaparecerían.

\footnotetext{
${ }^{9}$ El Artículo 641 E.T. establece que las personas o entidades obligadas a declarar, que presenten las declaraciones tributarias en forma extemporánea, deberán liquidar y pagar una sanción por cada mes o fracción de mes calendario de retardo, equivalente al cinco por ciento (5\%) del total del impuesto a cargo o retención objeto de la declaración tributaria, sin exceder del ciento por ciento $(100 \%)$ del impuesto o retención, según el caso. Adicionalmente, señala que esta sanción se cobrará sin perjuicio de los intereses que origine el incumplimiento en el pago del impuesto, anticipo o retención a cargo del contribuyente, responsable o agente retenedor. El Artículo 642 E.T. sanciona la extemporaneidad en la presentación de la declaración con posterioridad al emplazamiento para declarar. Por su parte, el Artículo 634 E.T. señala que los contribuyentes, agentes retenedores o responsables de los impuestos administrados por la Dirección de Impuestos y Aduanas Nacionales, que no cancelen oportunamente los impuestos, anticipos y retenciones a su cargo, deberán liquidar y pagar intereses moratorios por cada día calendario de retardo en el pago. ${ }^{10}$ El Artículo 27 de la Ley General Tributaria española establece que los recargos por presentación extemporánea son prestaciones accesorias que deben satisfacer los obligados tributarios como consecuencia de la presentación de autoliquidaciones o declaraciones fuera de plazo sin requerimiento previo de la Administración tributaria.
} 
Como quiera que la firma de un acuerdo de pago es precedida de un estudio del flujo de caja del contribuyente y respaldada con una garantía aportada por este, el crédito fiscal se recupera manteniendo el valor real de la obligación, interrumpiendo los términos de prescripción de la acción de cobro.

El inciso $1^{\circ}$ del Artículo 814 del Estatuto Tributario establece que el Subdirector de Cobranzas y los Administradores de Impuestos Nacionales podrán, mediante resolución, conceder facilidades para el pago al deudor o a un tercero a su nombre, hasta por cinco (5) años, para el pago de los impuestos de timbre, de renta y complementarios, sobre las ventas y la retención en la fuente, o de cualquier otro impuesto administrado por la Dirección General de Impuestos Nacionales (hoy DIAN), así como para la cancelación de los intereses y demás sanciones a que haya lugar, siempre que el deudor o un tercero a su nombre constituya fideicomiso de garantía, ofrezca bienes para su embargo y secuestro, garantías personales, reales, bancarias o de compañías de seguros, o cualquiera otra garantía que respalde suficientemente la deuda a satisfacción de la administración.

Sin embargo, teniendo en cuenta que el Artículo 580-1 del Estatuto Tributario, modificado por el Artículo 270 de la Ley 1819 de 2016, solamente concede un término de dos (2) meses para pagar las declaraciones de retención en la fuente, la administración tributaria ha rechazado las solicitudes de facilidades de pago por el mencionado concepto, a pesar de que el Artículo 814 del Estatuto Tributario, el cual no ha sido modificado por las Leyes 1430 de 2010 y 1819 de 2016, incluye las retenciones en la fuente dentro de los conceptos objeto de la facilidad de pago.
$\mathrm{Al}$ respecto, debe tenerse en cuenta que Cecilia Rico (2011), funcionaria de la DIAN, al referirse a los aspectos a evaluar en las solicitudes de facilidad de pago, sostuvo que tiene derecho a solicitar facilidad de pago como mecanismo para poner al día las obligaciones adeudadas a la Nación todo contribuyente que tenga obligaciones de naturaleza tributaria, aduanera y/o cambiaria que sea administrada por la DIAN, siempre y cuando no tenga restricción legal y expresa en la ley, reglamento, orden o instrucción interna, y siempre y cuando exista título claro, expreso y exigible.

Por lo anterior, como en presencia de una declaración ineficaz no hay una obligación clara, expresa y exigible, la administración no acepta facilidades de pago por concepto de retenciones en la fuente. Sin embargo, para evitar controversias con los contribuyentes, quienes exigen el otorgamiento de facilidades de pago por retenciones en la fuente, habría sido mejor que el Artículo 814 E.T. estuviera en armonía con lo dispuesto en el Artículo 580-1 E.T., disponiendo la no aceptación de facilidades de pago por concepto de retenciones en la fuente.

\section{Soluciones a la problemática asocia- da con la consagración de la ineficacia de las declaraciones de retención en la fuente}

\section{A. Otorgar validez a las declaraciones de retención en la fuente presentadas sin pago total}

La primera propuesta de solución a la problemática asociada con la consagración de la ineficacia de las declaraciones de retención en la fuente presentadas sin pago total 
consiste en considerar tales declaraciones como válidas, al igual que las demás declaraciones tributarias presentadas sin pago. Para ello, deberá derogarse el Artículo 580-1 del Estatuto Tributario y el parágrafo $5^{\circ} \mathrm{del}$ Artículo 1.6.1.13.2.35. del Decreto 220 del 7 de febrero del 2017, que modificó el Decreto 1625 de 2016 Único reglamentario en materia tributaria.

De esa manera, quedarían solucionados el problema de la ausencia de título ejecutivo y la imposibilidad de practicar medidas cautelares expuesto en el capítulo segundo del presente trabajo, por las razones que se expondrán a continuación:

El legislador, al consagrar la ineficacia, pretendió que las declaraciones de retención en la fuente se presentaran con pago o que el pago se realizara dentro de los dos (2) meses siguientes al vencimiento del plazo para declarar. Sin embargo, se ha evidenciado que algunos contribuyentes han seguido presentando sus declaraciones sin pago y no han realizado el pago de la declaración dentro del término anteriormente señalado. Adicionalmente, la administración no tiene las herramientas para hacer efectivo el cobro de las declaraciones de retención en la fuente ineficaces, que son el embargo y el secuestro, por cuanto las mencionadas declaraciones no prestan mérito ejecutivo. Igualmente, debe señalarse que resulta contradictorio que, mientras que el numeral $1^{\circ}$ del Artículo 828 del Estatuto señala que prestarán mérito ejecutivo las liquidaciones privadas y sus correcciones contenidas en las declaraciones tributarias presentadas desde el vencimiento de la fecha para su cancelación, el Artículo 580-1 ibídem señala que las declaraciones de retención en la fuente presentadas sin pago total, respecto de las cuales ha transcurrido el término de dos (2) meses sin que el deudor haya efectuado el pago, no son exigibles, en la medida en que son ineficaces y no pueden cobrarse al deudor.

Teniendo en cuenta lo antes expuesto, tenemos que si se deroga el Artículo 5801 del Estatuto Tributario y el parágrafo $5^{\circ}$ del Artículo 1.6.1.13.2.35. del Decreto 220 del 7 de febrero del 2017, que modificó el Decreto 1625 de 2016 Único reglamentario en materia tributaria, la administración tributaria tendría un título ejecutivo para hacer el cobro inmediato de los valores declarados tanto al agente retenedor (deudor principal) como a los deudores subsidiarios, y podría practicar medidas cautelares para garantizar el pago de las obligaciones, que son medidas que resultan más efectivas para el pago de los valores declarados en las declaraciones de retención en la fuente que la misma ineficacia. Adicionalmente, la administración no tendría que agotar el procedimiento oficial de aforo, que es largo y dispendioso, para que se conforme el título ejecutivo.

Así mismo, al otorgar efectos legales a las declaraciones de retención en la fuente presentadas sin pago, las mismas pueden ser allegadas como prueba dentro del proceso penal por omisión de agente retenedor sin que la administración tributaria se exponga a que sean rechazadas o no valoradas por el fiscal o por el juez, quien puede aducir que las declaraciones no tienen efecto legal alguno, ni siquiera en el campo penal.

Por su parte, al administrado no se le hace más gravosa su situación en el caso de que transcurridos los dos (2) meses contados a partir del vencimiento del plazo para decla- 
rar no haya logrado realizar el pago total, en la medida en que si presentó su declaración oportunamente, no tendría que pagar la sanción por extemporaneidad.

La presente propuesta de solución tiene su apoyo en la crítica realizada por Olga Lucía González Parra (2011), quien al referirse al Artículo 15 de la Ley 1430 de 2010 sostuvo lo siguiente:

(...) Sin embargo, no es claro si la administración ha ganado con esta reforma. Antes de la modificación de la Ley 1430, con una declaración de retención en la fuente sin pago, la administración tenía un título ejecutivo con el que podía iniciar un proceso de cobro coactivo. Ahora, al decir que dichas declaraciones son ineficaces, se está diciendo que no producen efecto jurídico alguno y, por lo tanto, no cobran firmeza ni prestan mérito ejecutivo. En este nuevo escenario, la administración tendrá que iniciar el procedimiento de aforo emplazamiento para declarar, resolución sanción por no declarar y liquidación de aforo para instar al contribuyente a que declare y pague las retenciones, los intereses y las sanciones por extemporaneidad o por no declarar, según avance el procedimiento. Y si el contribuyente no paga, solo se podrá ir al cobro coactivo cuando se notifique la liquidación de aforo.

Si bien se hizo más gravosa la situación del declarante, porque antes de la reforma el no pago de lo liquidado en la declaración de retención en la fuente solo acarreaba intereses moratorios y ahora a éstos se suma la sanción por extemporaneidad, o la sanción por no declarar, también es cierto que la situación será más desgastante para la ad- ministración si el declarante no se intimida por las sanciones y se ve obligada a agotar todo el procedimiento de aforo para generar un título ejecutivo (...).

En este sentido, para evitar que la administración tributaria se desgaste realizando la determinación de la obligación tributaria, que a su vez fue hecha por el contribuyente en su denuncio rentístico, y para que la administración recaude efectivamente los valores retenidos, se impone derogar el Artículo 580-1 del Estatuto Tributario y el parágrafo $5^{\circ}$ del Artículo 1.6.1.13.2.35. del Decreto 220 del 7 de febrero del 2017, que modificó el Decreto 1625 de 2016 Único reglamentario en materia tributaria.

En lo referente a las dificultades de aplicación de la presente propuesta, tenemos que la implementación de esta implica la modificación del aplicativo SIPAC, que es un sistema de administración de cartera empleado para la gestión de los expedientes de cobro, para que figuren como cobrables las retenciones en la fuente.

Actualmente, en el aplicativo SIPAC no figuran cargadas las declaraciones de retenciones en la fuente, por cuanto desde la entrada en vigencia de la Ley 1430 de 2010 el aplicativo fue modificado para que no se cobraran esas obligaciones dentro de él por la ausencia del título ejecutivo. Ni siquiera permite la elaboración de mandamientos y de oficios persuasivos penalizables, que son las herramientas de presión para lograr el pago de las obligaciones.

Si se hacen los ajustes al aplicativo SIPAC para que las declaraciones de retención en la fuente presentadas figuren como cobrables, 
se podrían gestionar, a través del aplicativo y no por fuera de él, mandamientos de pago, oficios persuasivos penalizables y embargos por declaraciones de retención en la fuente presentadas sin pago, con lo cual se evitaría la realización de actuaciones manuales y quedaría la trazabilidad de las gestiones realizadas.

De otra parte, teniendo en cuenta que con la modificación propuesta la administración se encontraría facultada para otorgar facilidades de pago por concepto de retenciones en la fuente hasta por un término de cinco (5) años, tenemos que el término es muy largo si se quiere que la administración cuente con un flujo constante de recursos.

Sobre el particular, Rico, C. (2011), al referirse a los ajustes que se han pensado hacer o se han realizado a las facilidades de pago, sostuvo que el plazo de la facilidad de pago no debe extenderse más allá de treinta y seis (36) meses, por cuanto si bien es un instrumento que permite la recuperación del crédito fiscal, la suscripción de la misma suspende el proceso de cobro, siendo preciso sopesar los beneficios derivados de pagos parciales frente a la posibilidad de recuperar más rápidamente el crédito al aplicar las medidas cautelares y/o continuar con las acciones propias del proceso que inducen el pago de las obligaciones. Además, manifiesta que, ante la eventualidad de una denuncia penal por obligaciones asociadas al pago del IVA, muchos morosos optan por cancelar mientras que, en el caso de la suscripción de facilidades de pago, se cancelan las primeras cuotas para lograr la suspensión de las medidas cautelares y posteriormente se insolventan, perdiéndose la oportunidad de recuperar el crédito fiscal vía embargos y secuestro de bienes.

Teniendo en cuenta que el otorgamiento de las facilidades de pago implica no practicar medidas cautelares y suspender el proceso administrativo de cobro, en este trabajo se propone incluir un parágrafo en el Artículo 814 E.T. en el cual se contemple el pago de las retenciones en la fuente como un requisito para el otorgamiento de las facilidades, así como el previsto en el numeral $4^{\circ}$ del Artículo $10^{\circ}$ de la Ley 1116 de 2006 (Régimen de insolvencia empresarial en la República de Colombia), antes de la modificación de la Ley 1429 de 2010, para los acuerdos de reorganización. En ese sentido, el Artículo 814 E.T. quedaría así:

\section{ARTÍCULO 814.FACILIDADES PARA} EL PAGO. (Artículo modificado por el Artículo 91 de la Ley 6 de 30 de junio de 1992). (Valores absolutos convertidos a UVT por disposición del artículo 868-1 del Estatuto Tributario, modificado por el artículo 51 de la Ley 1111 de 27 de diciembre de 2006). El Subdirector de Cobranzas y los Administradores de Impuestos Nacionales, podrán mediante resolución conceder facilidades para el pago al deudor o a un tercero a su nombre, hasta por cinco (5) años, para el pago de los impuestos de timbre, de renta y complementarios, sobre las ventas o de cualquier otro impuesto administrado por la Dirección General de Impuestos Nacionales, así como para la cancelación de los intereses y demás sanciones a que haya lugar, siempre que el deudor o un tercero a su nombre constituya fideicomiso de garantía, ofrezca bienes para su embargo y secuestro, garantías personales, 
reales, bancarias o de compañías de seguros, o cualquiera otra garantía que respalde suficientemente la deuda a satisfacción de la Administración. Se podrán aceptar garantías personales cuando la cuantía de la deuda no sea superior a 3.000 UVT.

(\$ 95.577.000 Base 2017: UVT 3.000 a \$ 31.859; Resolución DIAN No. 71 de 21 de noviembre de 2016).

Igualmente podrán concederse plazos sin garantías, cuando el término no sea superior a un año y el deudor denuncie bienes para su posterior embargo y secuestro.

\section{(Incisos 3 y 4 derogados por el artículo} 21 de la Ley 1066 de 29 de julio de 2006).

\section{(Inciso 5 adicionado por el Artículo 114 de la Ley 488 de 24 de diciembre de 1998). En casos especiales y solamente bajo la competencia del Director de Impuestos Na- cionales, podrá concederse un plazo adi- cional de dos (2) años al establecido en el inciso primero de este artículo.}

PARÁGRAFO. La solicitud de facilidad de pago deberá presentarse acompañada de los documentos que acrediten el pago de las obligaciones vencidas por retenciones en la fuente (...).
Igualmente, se deberá modificar el Artículo 1.6.2.6.2. del Decreto único reglamentario en materia tributaria (1625 de 2016), relacionado con la determinación de la cuantía de las obligaciones fiscales en mora al momento de expedir las facilidades de pago, por cuanto deben excluirse de esa relación las obligaciones vencidas por retenciones en la fuente cuyo pago debe acreditarse con la presentación de la solicitud conforme al parágrafo del Artículo 814 E.T.

\section{B. Fiscalización oportuna de los contri- buyentes omisos en la presentación de las declaraciones de retención en la fuente}

Teniendo en cuenta que con la derogatoria de la ineficacia persiste el problema relacionado con los contribuyentes omisos, esto es, aquellos que no presentan las declaraciones de retención en la fuente, se requiere que la administración genere riesgo subjetivo mediante la fiscalización oportuna. Para ello, se requiere adelantar los siguientes pasos:

1. En primer lugar, es necesario que se proponga a la Dirección de Gestión Organizacional un programa de fiscalización de omisos ${ }^{11}$ en retención en la fuente, por cuanto los programas han estado enfocados en los omisos e inexactos en el impuesto sobre la renta y en el impuesto al valor agregado IVA. 
Con la implementación de un programa de omisos en retención en la fuente, las Divisiones de Gestión de Fiscalización de las Direcciones Seccionales adelantarían, sin necesidad de solicitud por parte de las otras divisiones o por parte de terceros, las investigaciones por el incumplimiento en el deber formal de declarar las retenciones en la fuente practicadas en determinado período.

2. Reducción del término que tienen las Divisiones de Gestión de Fiscalización para adelantar las investigaciones por omisos en retención en la fuente.

Esta propuesta tiene su fundamento en el hecho de que en el transcurso de los cinco (5) años que tiene la administración para adelantar el correspondiente proceso de determinación puede variar la situación económica del contribuyente, esto es, puede haber sido admitido a un trámite de liquidación judicial dentro del cual es más difícil obtener el pago de las retenciones en la fuente practicadas y que no han sido declaradas por los agentes de retención.

Adicionalmente, como se señaló en el momento de referirnos al procedimiento oficial de aforo, debe tenerse en cuenta que para funcionarios de la administración tributaria, como Álvaro Sánchez Uribe (2012), el término para proferir la liquidación oficial de aforo y la resolución sanción por no declarar es considerado extenso, por cuanto en estos momentos la administración dispone de los últimos avances tecnológicos, aunado a las disposiciones de control como la información exógena y el intercambio de datos con fines de fiscalización, por lo cual no se justifica mantener el término de cinco (5) años contados a partir del vencimiento del plazo para declarar para que la administración profiera una resolución sanción por no declarar y la correspondiente liquidación oficial de aforo.

Por ello, en el presente trabajo, se propone reducir el término de caducidad de la facultad sancionadora previsto en el Artículo 638 del Estatuto Tributario, al igual que el término para proferir la liquidación oficial de aforo contemplado en el Artículo 717 del Estatuto Tributario a tres (3) años aplicable solamente a las declaraciones de retención en la fuente.

En consecuencia, los Artículos 638 y 717 del Estatuto Tributario quedarían de la siguiente manera:

ARTíCULO 638. Cuando las sanciones se impongan en resolución independiente, deberá formularse el pliego de cargos correspondiente dentro de los dos años siguientes a la fecha en que se presentó la declaración de renta y complementarios o de ingresos y patrimonio, del período durante el cual ocurrió la irregularidad sancionable o cesó la irregularidad, para el caso de las infracciones continuadas. Salvo en el caso de la sanción por no declarar, de los intereses de mora, y de las sanciones previstas en los Artículos 659, 659-1 y 660 del Estatuto Tributario, las cuales caducan en el término de cinco años.

Tratándose de la resolución sanción por no declarar por concepto de retenciones en la fuente, el término de caducidad de la facultad sancionadora será de tres (3) años contados a partir del vencimiento del plazo para declarar. 
Vencido el término de respuesta del pliego de cargos, la administración tributaria tendrá un plazo de seis meses para aplicar la sanción correspondiente, previa la práctica de las pruebas a que hubiere lugar.

ARTÍCULO 717. Agotado el procedimiento previsto en los Artículos 643, 715 y 716, la administración podrá, dentro del término de los cinco (5) años siguientes al vencimiento del plazo señalado para declarar, determinar mediante una liquidación de aforo, la obligación tributaria al contribuyente, responsable, declarante, que no haya declarado.

En el caso de las retenciones en la fuente, el término que tiene la administración para proferir la liquidación oficial de aforo a los agentes retenedores será de tres (3) años siguientes al vencimiento del plazo para declarar.

Para aplicar la presente propuesta, es necesario conocer la cantidad de investigaciones pendientes de apertura que tienen cada una de las Divisiones de Gestión de Fiscalización de todas las Direcciones Seccionales para saber si se puede implementar de manera inmediata. En caso de que el Director de Gestión de Fiscalización considere que el volumen de las investigaciones dificulta la implementación de la propuesta, debería adoptarse un programa que procure por el inicio inmediato de las investigaciones pendientes, de manera que en un término no superior a un (1) año se pueda implementar la propuesta que se pretende poner en práctica.

1. Implementar el procedimiento de la liquidación provisional para la determinación de las retenciones en la fuente.
En la exposición de motivos del proyecto de ley "por medio de la cual se adopta una reforma tributaria estructural, se fortalecen los mecanismos para la lucha contra la evasión y la elusión fiscal, y se dictan otras disposiciones", que culminó en la Ley 1819 de 2016, se expusieron los siguientes argumentos para modificar y reglamentar la liquidación provisional:

\subsubsection{Proceso de liquidación provisional (...)}

Para la solución del problema de la cobertura del control y capacidad operativa de la DIAN, se crea el "Procedimiento especial para la fiscalización y control electrónico". En este sentido, se abrevia la etapa de fiscalización (cuatro meses) con la creación de la Liquidación Provisional, que es adecuada jurídicamente entre otros, para: i) la modificación de la declaración (inexactos), y ii) la determinación del importe del impuesto para el no declarante (omisos).

La Liquidación Provisional puede ser aceptada o rechazada por el contribuyente. De ser aceptada se convertirá, en definitiva, de tal forma que lo que correspondería sería el pago o la facilidad de pago de la misma (se da la categoría de título ejecutivo - Presta mérito ejecutivo) y en caso de que la Liquidación Provisional fuera rechazada, remplazaría para todos los efectos el Pliego de Cargos, el Requerimiento Especial o el Emplazamiento previo por no declarar, según el caso (...).

Del texto transcrito se concluye que el legislador modificó y reglamentó la liquidación provisional en los Artículos 255, 256, $257,258,259,260$ y 261 de la Ley 1819 de 2016, con el fin de que la administración 
solucionara el problema de la cobertura del control y la capacidad operativa. Sin embargo, en el parágrafo $1^{\circ}$ del Artículo 255 de la Ley 1819 de la Ley 1819 de 2016, que modificó el Artículo 764 E.T., se estableció un tope de ingresos y de patrimonio que limita la aplicación del procedimiento, por lo cual se requiere modificar este artículo para que el procedimiento de la liquidación provisional sea aplicable a las retenciones en la fuente sin importar el tope de ingresos y de patrimonio del agente retenedor.

Por lo anterior, el Artículo 764 E.T. quedaría así:

ARTíCULO 764. La Administración Tributaria podrá proferir Liquidación Provisional con el propósito de determinar y liquidar las siguientes obligaciones:

a) Impuestos, gravámenes, contribuciones, sobretasas, anticipos y retenciones que hayan sido declarados de manera inexacta $o$ que no hayan sido declarados por el contribuyente, agente de retención o declarante, junto con las correspondientes sanciones que se deriven por la inexactitud u omisión, según el caso;

b) Sanciones omitidas o indebidamente liquidadas en las declaraciones tributarias;

c) Sanciones por el incumplimiento de las obligaciones formales.

Para tal efecto, la Administración Tributaria podrá utilizar como elemento probatorio la información obtenida de conformidad con lo establecido en el Artículo 631 y a partir de las presunciones y los medios de prueba contemplados en el Estatuto Tributario, y que permita la proyección de los factores a partir de los cuales se establezca una presunta inexactitud, impuestos, gravámenes, contribuciones, sobretasas, anticipos, retenciones y sanciones. La Liquidación Provisional deberá contener lo señalado en el Artículo 712 del Estatuto Tributario.

PARÁGRAFO 1. En los casos previstos en este artículo, a excepción de la determinación de las retenciones y las sanciones relacionadas con la omisión en la presentación de las declaraciones de retención en la fuente, solo se proferirá Liquidación Provisional respecto de aquellos contribuyentes que, en el año gravable inmediatamente anterior al cual se refiere la Liquidación Provisional, hayan declarado ingresos brutos iguales o inferiores a quince mil (15.000) UVT o un patrimonio bruto igual o inferior a treinta mil (30.000) UVT, o que determine la Administración Tributaria a falta de declaración, en ningún caso se podrá superar dicho tope.

Tratándose de las retenciones y de las sanciones correspondientes no operarán los topes de ingresos y de patrimonio señalados en el inciso anterior.

PARÁGRAFO 2. En la Liquidación Provisional se liquidarán los impuestos, gravámenes, contribuciones, sobretasas, anticipos, retenciones y sanciones de uno o varios periodos gravables correspondientes a un mismo impuesto, que puedan ser objeto de revisión, o se determinarán las obligaciones formales que han sido incumplidas en uno $o$ más periodos respecto de los cuales no haya prescrito la acción sancionatoria.

PARÁGRAFO 3. La Administración Tributaria proferirá Liquidación Provisional 
con el propósito de determinar y liquidar el monotributo cuando los contribuyentes del mismo omitan su declaración o lo declaren de manera inexacta, junto con las correspondientes sanciones.

PARÁGRAFO 4. Cuando se solicite la modificación de la Liquidación Provisional por parte del contribuyente, el término de firmeza de la declaración tributaria sobre la cual se adelanta la discusión, se suspenderá por el término que dure la discusión, contado a partir de la notificación de la Liquidación Provisional.

De otra parte, para que la liquidación provisional sea congruente con la reducción del término de caducidad de la facultad sancionadora y del término para proferir la liquidación oficial de aforo, se propone modificar el literal b) del Artículo 764-1 E.T. para consagrar expresamente que la liquidación provisional por concepto de retención en la fuente debe ser proferida dentro de los tres (3) años siguientes al vencimiento del plazo para declarar. En ese sentido, el Artículo 764-1 E.T. quedaría así:

ARTÍCULO 764-1. La Liquidación Provisional deberá ser proferida en las siguientes oportunidades:

a) Dentro del término de firmeza de la declaración tributaria, cuando se trate de la modificación de la misma;

b) Dentro del término de cinco (5) años contados a partir de la fecha del vencimiento del plazo para declarar, cuando se trate de obligados que no han cumplido con el deber formal de declarar. Tratándose de la determinación de las retenciones y de las sanciones correspondientes, la administración debe proferir la liquidación provisional dentro del término de tres (3) años contados a partir del vencimiento del plazo para declarar.

c) Dentro del término previsto para imponer sanciones, cuando se trate del incumplimiento de las obligaciones distintas al deber formal de declarar.

Una vez proferida la Liquidación Provisional, el contribuyente tendrá un (1) mes contado a partir de su notificación para aceptarla, rechazarla o solicitar su modificación por una única vez, en este último caso deberá manifestar los motivos de inconformidad en un memorial dirigido a la Administración Tributaria.

Cuando se solicite la modificación de la Liquidación Provisional, la Administración Tributaria deberá pronunciarse dentro de los dos (2) meses siguientes al agotamiento del término que tiene el contribuyente para proponer la modificación, ya sea profiriendo una nueva Liquidación Provisional o rechazando la solicitud de modificación.

El contribuyente tendrá un (1) mes para aceptar o rechazar la nueva Liquidación Provisional, contado a partir de su notificación. En todos los casos, si el contribuyente opta por aceptar la Liquidación Provisional, deberá hacerlo en forma total.

PARÁGRAFO 1. La Liquidación Provisional se proferirá por una sola vez, sin perjuicio 
de que la Administración Tributaria pueda proferir una nueva con ocasión de la modificación solicitada por el contribuyente.

En ningún caso se podrá proferir Liquidación Provisional de manera concomitante con el requerimiento especial, el pliego de cargos o el emplazamiento previo por no declarar.

PARÁGRAFO 2. La Liquidación Provisional se considera aceptada cuando el contribuyente corrija la correspondiente declaración tributaria o presente la misma, en los términos dispuestos en la Liquidación Provisional y atendiendo las formas y procedimientos señalados en el Estatuto Tributario para la presentación y/o corrección de las declaraciones tributarias.

De igual manera se considera aceptada por el contribuyente, cuando este no se pronuncie dentro de los términos previstos en este artículo sobre la propuesta de Liquidación Provisional, en cuyo caso la Administración Tributaria podrá iniciar el procedimiento administrativo de cobro.

Cuando se trate del incumplimiento de otras obligaciones formales, distintas a la presentación de la declaración tributaria, se entenderá aceptada la Liquidación Provisional cuando se subsane el hecho sancionable y se pague o se acuerde el pago de la sanción impuesta, conforme las condiciones y requisitos establecidos en el Estatuto Tributario para la obligación formal que corresponda. En este caso, la Liquidación Provisional constituye título ejecutivo de conformidad con lo establecido en el artículo 828 del mismo Estatuto.
En cuanto a los problemas para implementación de la propuesta, tenemos que son los mismos que ha planteado la doctrina con ocasión de la regulación de la figura en el Estatuto Tributario y en la Ley 1819 de 2016, los cuales se exponen a continuación:

\section{Necesidad de proferir y notificar un acto administrativo previo antes de la} liquidación provisional.

Al respecto, García, B. (2017), al referirse a las liquidaciones provisionales, sostiene que la primera discusión que se generó respecto de estas liquidaciones, antes de la Ley 1819 de 2016, consistió en determinar la necesidad de proferir y notificar un acto administrativo previo, esto es, un pliego de cargos, un emplazamiento para declarar o un requerimiento especial. Para exponer dicha problemática, cita a Piza (2010), quien sobre el particular manifestó lo siguiente:

(...) debe tenerse en cuenta que para la expedición de la liquidación provisional, la Administración debe enviar al contribuyente un emplazamiento o requerimiento, en el que se le informe que no ha presentado la declaración tributaria y advertir la consecuencia jurídica dado su incumplimiento, toda vez que la determinación del tributo por liquidación provisional también exige respeto del derecho de defensa y contradicción del contribuyente (...).

De manera que, para Piza (2010) la administración debe proferir un acto previo que garantice el derecho de contradicción y defensa del contribuyente en cumplimiento del debido proceso previsto en el Artículo 29 de la Constitución Política. 
Sin embargo, con la expedición de la Ley 1819 de 2016, el tema se torna más complejo, por cuanto en algunos casos la liquidación provisional tiene el carácter de acto definitivo y en otros es un acto preparatorio.

En efecto, de acuerdo con lo dispuesto en el parágrafo $2^{\circ}$ del Artículo 764-1 E.T., la liquidación provisional tiene carácter de acto preparatorio si el contribuyente la acepta de manera expresa, por cuanto debe desplegar una actuación posterior a la notificación.

Así, cuando el contribuyente acepta la liquidación provisional, debe corregir la correspondiente declaración tributaria, en el caso de inexactitud, o presentar la misma, en el evento de omisión, en los términos dispuestos en la Liquidación Provisional $\mathrm{y}$ atendiendo las formas y procedimientos señalados en el Estatuto Tributario para la presentación y/o corrección de las declaraciones tributarias.

Igualmente, cuando se trate del incumplimiento de otras obligaciones formales distintas a la presentación de la declaración tributaria, si el contribuyente acepta la Liquidación Provisional, deberá subsanar el hecho sancionable y pagar o acordar el pago de la sanción impuesta, conforme las condiciones y requisitos establecidos en el Estatuto Tributario para la obligación formal que corresponda.

En estos casos, debe entenderse que la liquidación provisional tiene el carácter de acto preparatorio y, por ello, no sería necesario expedir otro acto administrativo mediante el cual se le informe al contribuyente sobre la inexactitud o la omisión.
No obstante, cuando el contribuyente acepta en forma tácita la liquidación provisional, por cuanto no se pronuncia dentro de los términos previstos en el Artículo 764-1 E.T., esto es, dentro del mes siguiente a la notificación de la liquidación provisional inicial o de la nueva liquidación provisional proferida con ocasión de la solicitud de modificación, la liquidación provisional tiene el carácter de acto definitivo, por cuanto la administración puede iniciar el procedimiento administrativo de cobro. En este último caso, se puede considerar que la norma es una manifestación del principio de eficiencia, ya que no se requiere que la administración emita un acto administrativo posterior para ejecutar la liquidación provisional, pero dado su carácter definitivo es cuestionable si es necesario que en los casos en los que el contribuyente guarda silencio sea necesario proferir una actuación posterior, con lo cual la liquidación provisional tendría carácter preparatorio en todos los casos.

\section{Uso del procedimiento de liquidación provisional.}

El principal problema que enfrenta la presente propuesta consiste en que, efectivamente, la administración tributaria haga uso del procedimiento. La liquidación provisional no es una figura nueva dentro del ordenamiento jurídico colombiano. En el Estatuto Tributario se encontraba contemplada en el Artículo 764 E.T., antes de la Ley 1819 de 2016, pero la administración prefirió agotar el procedimiento oficial de aforo explicado anteriormente. Por lo cual se requiere que la misma administración tributaria se convenza de que es necesario hacer uso de la figura de la liquidación provisional para la determinación de las retenciones en la fuente no 
declaradas, por cuanto es más expedito que el trámite del procedimiento oficial de aforo y, además, se utiliza la misma información que se requiere para la determinación del impuesto dentro del procedimiento oficial.

En relación con los problemas de inconstitucionalidad de la propuesta, consideró que, al establecerse un procedimiento de determinación paralelo al procedimiento oficial de aforo con menos garantías para el contribuyente, el mismo puede ser eventualmente objeto de demandas de inconstitucionalidad por vulneración al derecho a la igualdad, previsto en el Artículo 13 de la Constitución Política, y al debido proceso, contemplado en el Artículo 29 de la Carta Magna.

\section{Conclusiones}

En este artículo, se quisieron abordar los problemas que ha tenido la administración para hacer el cobro de las declaraciones de retención en la fuente presentadas sin pago total y de las retenciones que no son declaradas por el agente de retención, teniendo de presente la importancia del mecanismo para las finanzas públicas, por cuanto se consagró legalmente con el propósito de que el recaudo de los impuestos se realizara en el mismo período gravable en el cual se llevaron a cabo operaciones gravadas con los impuestos en los cuales aplica la retención y, adicionalmente, se fundamenta en el principio de eficiencia consagrado en el Artículo 363 de la Constitución Política por las siguientes razones:

- Permite el recaudo simultáneo del impuesto en el momento de obtención de los ingresos.
- Simplifica el trabajo de la administración tributaria al delegar la tarea del recaudo en el agente retenedor.

- Permite un recaudo poco costoso y cómodo para los contribuyentes.

- Permite que el Estado perciba un flujo constante de ingresos fiscales.

- Elimina algunas posibilidades de evasión y elusión fiscal, por cuanto facilita la identificación de contribuyentes que podrían permanecer ocultos o que son difíciles de ubicar directamente.

En relación con los mecanismos jurídicos empleados por el legislador para recaudar las retenciones en la fuente, tenemos, en primer lugar, la sanción penal que en cierta medida coerciona a los agentes retenedores a realizar el pago de las declaraciones de retención en la fuente. Sin embargo, para que la sanción penal resulte efectiva, se requiere que la validez de las declaraciones que sirven como prueba de la comisión de la conducta punible no pueda ser controvertida. Por ello, en el momento de la consagración de la sanción penal, el legislador nunca contempló eventos de declaraciones de retención en la fuente que se tienen por no presentadas y declaraciones ineficaces.

No obstante, se buscaron medidas desesperadas para que el pago se hiciera de manera concomitante con la presentación de la declaración. Primero, con la Ley 1066 de 2006 se introdujo un literal e) al Artículo 580 E.T. para consagrar como una de las causales para tener por no presentadas las declaraciones de retención en la fuente el hecho de haberla presentado sin pago. El procedimiento para tener por no presentada la declaración no fue reglamentado, sino que fue producto 
de la creación jurisprudencial, que señaló que debía expedirse un auto declarativo por parte de la División de Fiscalización dentro del término de firmeza de la declaración, el cual era de dos (2) años antes de la Ley 1819 de 2016. Si el acto declarativo no era proferido, la declaración era tenida como válida. Al asignarle la competencia para proferir el auto declarativo a la División de Fiscalización, en esta dependencia de la Dirección Seccional de cierta manera aumentó la carga laboral.

Por lo tanto, en segundo lugar, el legislador resolvió que era mejor que se consagrara que el efecto del no pago oportuno de la declaración de retención en la fuente no debía ser el tenerla como no presentada, sino que la misma no produjera ningún efecto legal, sin necesidad de acto administrativo alguno, tal como quedó contemplado en el Artículo 15 de la Ley 1430 de 2010, con el fin de acelerar el recaudo de las retenciones y lograr que los agentes retenedores presentaran con pago las declaraciones.

La ineficacia consagrada en la Ley 1430 de 2010 es diferente a la ineficacia contemplada en el Derecho privado y en el Derecho administrativo, en la medida en que no es saneable, por cuanto ni la ratificación ni el transcurso del tiempo pueden hacer subsistir la declaración ineficaz, por lo cual el agente de retención debe presentar nuevamente la declaración y pagar la sanción por extemporaneidad, pese a que inicialmente pudo haberla presentado oportunamente.

Sin embargo, el legislador olvidó que la presentación de la declaración y el pago están sujetos, en principio, a la voluntad del contribuyente. También desconoció que ante la presentación sin pago de las declaraciones de retención en la fuente era necesario que la administración coercionara al contribuyente para la declaración y el pago de la obligación, pero ello no fue posible por cuanto con la ineficacia se les cercenaron todos los efectos a las declaraciones.

Como no se cumplieron los objetivos del legislador en el momento de expedir la Ley 1430 de 2010, mediante las amnistías tributarias consagradas en las Leyes 1607 de 2012, 1739 de 2014 y 1819 de 2016 se estableció la posibilidad de presentar las declaraciones de retención con el pago del impuesto, sin el pago de intereses ni de sanciones, con lo cual se reconoció que la figura de la ineficacia no había sido efectiva.

En el año 2016, el legislador fue consciente de que, en algunos casos, los contribuyentes presentaron sus declaraciones oportunamente, pero por alguna circunstancia el pago figuraba como realizado al día siguiente o dentro del mismo mes, lo cual implicó para el contribuyente el desgaste de volver a presentar la declaración y de pagar una sanción por extemporaneidad, pese a que la declaración inicial se presentó oportunamente. Por lo anterior, con la reforma tributaria de la Ley 1819 de 2016 se le dio un plazo de dos (2) meses al contribuyente para que realizara el pago de la declaración presentada oportunamente, sin atreverse a derogar de una vez por todas el Artículo 580-1 E.T.

En el caso de que no se efectúe el pago de la declaración de retención dentro del término señalado anteriormente, la declaración deviene en ineficaz y se considera que el contribuyente se encuentra omiso en la presentación de la misma, por lo cual le 
corresponde a la administración tributaria iniciar el correspondiente procedimiento oficial de aforo, por cuanto la declaración dejó de prestar mérito ejecutivo.

En ese sentido, con la expedición de la Ley 1819 de 2016, las declaraciones tributarias pueden clasificarse en:

1. Declaraciones válidas, las cuales prestan mérito ejecutivo.

2. Declaraciones que se tienen por no presentadas que prestan mérito ejecutivo mientras la administración no profiera el auto declarativo.

3. Declaraciones de retención en la fuente que son ineficaces si el pago de la declaración no se efectúa dentro de los dos (2) meses siguientes contados a partir del vencimiento del plazo para declarar.

Respecto de estas últimas y ante la precariedad del título, es necesario que, en el evento en que no se paguen las declaraciones, se inicie el proceso oficial de aforo para constituir el título ejecutivo, el cual supone una mayor carga para la administración tributaria. Adicionalmente, debe tenerse en cuenta que este proceso no se inicia de manera inmediata, por cuanto conforme a lo dispuesto en el Artículo 717 del Estatuto Tributario, la administración deberá adelantar este procedimiento dentro de los cinco (5) años siguientes al vencimiento del plazo señalado para declarar, término que ha sido considerado extenso por Álvaro Sánchez Uribe (2012) por disponer la administración de suficientes herramientas de información. En este sentido, si la administración demora el inicio de los procesos de determinación cuando comience las investigaciones puede tener inconvenientes como las dificultades para ubicar al deudor o la insolvencia del mismo.

Así mismo, para que se adelante la investigación contra un contribuyente que ha presentado declaraciones de retención en la fuente ineficaces o que no las ha presentado, se requiere que sea incluido en un programa de fiscalización, sea denunciado por un tercero o se solicite la investigación por parte de las dependencias y/o grupos de las Divisiones de Gestión de Cobranzas y/o Recaudo y Cobranzas y otras divisiones de la Dirección Seccional. De lo contrario, puede escapar del control de la administración y puede optar por no presentar las declaraciones de retención en la fuente.

En cuanto a las solicitudes de investigación realizadas por funcionarios de la administración, tenemos que el inconveniente de estas solicitudes radica en que, en algunos casos, cuando el funcionario de Cobranzas se da cuenta de la omisión o ineficacia de las declaraciones de retención en la fuente, ya es muy difícil procurar el pago de estas, por cuanto puede que el agente de retención se encuentre insolvente.

De esta manera, la gestión del funcionario de Cobranzas para obtener el pago de las declaraciones de retención en la fuente ineficaces se limita a proferir el oficio persuasivo penalizable y enviar los insumos a la Unidad Penal, con el riesgo de que la Fiscalía y el Juez Penal desestimen las declaraciones por no producir ningún efecto y a solicitar las investigaciones a la División de Gestión de Fiscalización, por cuanto no puede proferir 
mandamientos de pago ni decretar medidas cautelares, ya que no cuenta con un título ejecutivo.

Dentro del procedimiento oficial de aforo, la administración tributaria reconoce la presunción de veracidad de la declaración tributaria, conforme a lo dispuesto en el Artículo 746 del Estatuto Tributario, a pesar de que el Artículo 580-1 del Estatuto Tributario considera que la declaración ineficaz no produce efecto legal alguno. Sin embargo, debe comprobar los hechos declarados en una declaración ineficaz por medio de la práctica de una inspección tributaria o una inspección contable. En el caso de que la contabilidad del contribuyente no coincida con los hechos declarados por el contribuyente en la declaración ineficaz, prevalece la contabilidad, conforme a lo dispuesto en el Artículo 775 del Estatuto Tributario.

Contra la sanción por no declarar y la liquidación oficial de aforo procede el recurso de reconsideración, el cual deberá interponerse ante la oficina competente para conocer los recursos tributarios de la Administración de Impuestos que hubiere practicado el acto respectivo, dentro de los dos (2) meses contados a partir de la notificación de los mencionados actos administrativos. A su vez, la administración tributaria tendrá un (1) año para resolver los recursos de reconsideración, contado a partir de su interposición en debida forma. Dicho término se podrá suspender cuando se practique inspección tributaria, mientras dure la inspección, si esta se practica a solicitud del contribuyente, responsable, agente retenedor o declarante, y hasta por tres (3) meses cuando se practica de oficio.
Una vez resuelto el recurso de reconsideración de manera desfavorable para el contribuyente, este podrá formular demanda de nulidad y restablecimiento contra la resolución que impone la sanción por no declarar y contra la liquidación oficial de aforo dentro de los cuatro (4) meses siguientes contados a partir de la notificación de cada uno de los actos administrativos anteriormente mencionados.

Si el contribuyente no hubiere interpuesto los recursos por la vía gubernativa es procedente la revocatoria directa prevista en los Artículos 93 al 97 de la Ley 1437 de 2011 (CPACA). El término para ejercitar la revocatoria directa será de dos (2) años a partir de la ejecutoria del correspondiente acto administrativo. Por su parte, la administración deberá fallar las solicitudes de revocatoria directa dentro del término de un (1) año contado a partir de su petición en debida forma.

Teniendo en cuenta que los términos para que culmine el proceso oficial de aforo son muy largos, agravado por el hecho de que tanto la sanción por no declarar como la liquidación oficial de aforo son demandables ante la jurisdicción de lo contencioso administrativo, la consagración de la ineficacia de las declaraciones de retención en la fuente ha propiciado la evasión fiscal, por cuanto algunos contribuyentes han seguido apropiándose de los dineros públicos sin trasladarlos a la administración tributaria, sin ningún temor a ser fiscalizados por la omisión en la presentación de las declaraciones, aprovechando que los controles extensivos, que son aquellas acciones de control que realiza la Administración Tributaria a una gran cantidad de contribuyentes, de manera 
simultánea o en un lapso de tiempo relativamente corto, con el propósito de asegurar el cumplimiento tributario, o detectar el incumplimiento tributario a fin de aplicar las medidas correctivas que correspondan, no han sido eficientes, por las siguientes razones:

a) La selección del universo de los contribuyentes a fiscalizar se hace con base en los programas de fiscalización o en las solicitudes de investigación realizadas por las diferentes dependencias de las Direcciones Seccionales o en las denuncias de terceros. Sin embargo, se han detectado casos de contribuyentes que han dejado de presentar sus declaraciones durante un período de tiempo prolongado y no han sido fiscalizados por no haber sido seleccionados.

b)Los controles extensivos no se han realizado durante un periodo corto de tiempo contado a partir del incumplimiento de los deberes formales.

Además, como se dijo anteriormente, la Ley le concede a la administración tributaria un término de cinco (5) años para proferir la liquidación oficial de aforo, de los cuales la administración tributaria, en la mayoría de los casos, dedica los dos (2) primeros años para atender otras investigaciones pendientes y solamente a partir del tercer (3) año empieza a realizar los controles extensivos. Para los contribuyentes que no han sido admitidos a un proceso de insolvencia, no se presenta ningún inconveniente al realizar los controles a partir del tercer (3) año, pero para aquellos que durante el transcurso de los tres (3) años han sido admitidos a un trámite concursal de reorganización o liquidación, el ejercicio de los controles resulta tardío, por cuanto hay muy pocas probabilidades de que los contribuyentes en un trámite de insolvencia cumplan con el pago de la obligación que finalmente resulte determinada, si no se presentan inconvenientes en el proceso oficial de aforo como la no ubicación del contribuyente.

El segundo problema expuesto en el presente artículo derivado de la ineficacia de las declaraciones de retención en la fuente consiste en la ausencia de título ejecutivo, en la medida en que si bien el Artículo 828 del Estatuto Tributario señala taxativamente los documentos que prestan mérito ejecutivo, indicando que dentro de los mismos se encuentran las liquidaciones privadas y sus correcciones, contenidas en las declaraciones tributarias presentadas desde el vencimiento de la fecha para su cancelación, se requiere, además, que contengan obligaciones expresas, claras y exigibles, que las declaraciones sean eficaces. Por lo tanto, las declaraciones de retención en la fuente presentadas sin pago total, que son ineficaces, sin necesidad de acto administrativo que así lo declare, no prestan mérito ejecutivo, por cuanto al no producir efecto legal alguno, también se les cercenó su fuerza ejecutiva. Si se llegare a librar mandamiento de pago con base en una declaración ineficaz, el ejecutado podría proponer la excepción de falta de título ejecutivo, contemplada en el numeral $7^{\circ}$ del Artículo 831 del Estatuto Tributario, la cual está llamada a prosperar.

Ahora bien, con la Ley 1819 de 2016 se les otorgó a los contribuyentes un plazo de dos (2) meses para el pago de sus retenciones en la fuente. Sin embargo, ese término es insuficiente para iniciar el proceso administrativo de cobro. Si se inicia el proceso administra- 
tivo de cobro, la administración tributaria se expone a que dentro del trámite del proceso la declaración deje de ser exigible y se torne en ineficaz, por cuanto el proceso administrativo de cobro tiene un término de duración superior a los dos (2) meses.

Si la administración tributaria no puede hacer efectivo el cobro contra la persona jurídica que funge como agente retenedor por no tener un documento que presta mérito ejecutivo, tampoco puede hacer efectiva la responsabilidad subsidiaria contra los representantes legales, la cual está contemplada en los Artículos 573 y 798 del Estatuto Tributario, por cuanto debe dirigirse primero contra la entidad retenedora. Sin embargo, no puede realizarse el cobro contra el retenedor, ya que las declaraciones no prestan mérito ejecutivo.

En cuanto a los medios para procurar el pago de las obligaciones, tenemos que la administración puede practicar medidas cautelares, pero requiere de un título ejecutivo. Por lo tanto, con fundamento en el incumplimiento en el pago de una declaración ineficaz no se pueden decretar embargos y practicar el secuestro de bienes del deudor. En el proceso administrativo de cobro, las medidas cautelares más efectivas son el embargo de saldos bancarios y el embargo de créditos, en la medida en que le permiten a la administración tener títulos de depósito judicial que pueden ser aplicados directamente al pago de las obligaciones, sin necesidad de agotar el procedimiento de secuestro, avalúo y remate que debe surtirse en caso del embargo de bienes inmuebles.

Por lo anterior, tenemos que, si bien con la consagración de la ineficacia se pretendió que el agente de retención presentara y pagara voluntariamente las declaraciones de retención en la fuente dentro de los plazos previstos en la Ley, lo cierto es que dicha medida implicó quitarle a la administración una de las herramientas más efectivas para realizar el cobro, que consiste en la práctica de medidas cautelares. Para la práctica de medidas cautelares, la administración tributaria tiene que finalizar el largo proceso de determinación. Al finalizar el proceso, la administración puede encontrar que no existen bienes o créditos para embargar y secuestrar del agente retenedor que garanticen el pago de la obligación, por encontrarse en liquidación voluntaria o haber sido admitido al trámite de liquidación judicial.

Otro de los problemas emanados de la ineficacia de las declaraciones de retención en la fuente es la dificultad para obtener el pago de las retenciones en el trámite de liquidación judicial, por cuanto, si bien el literal g) del Artículo 49 de la Ley 1116 de 2006 establece como una de las causales para iniciar de manera inmediata el trámite de liquidación judicial el tener a cargo obligaciones vencidas por concepto de retenciones en la fuente, es muy poco probable que la administración haya culminado un procedimiento oficial de aforo antes de la apertura del trámite concursal.

La administración puede presentar como obligaciones contingentes en cuantía indeterminada las retenciones en la fuente omisas, pero al momento de adjudicar los bienes del deudor se requiere que las obligaciones con carácter contingente se encuentren determinadas, por cuanto el liquidador no puede proceder a realizar adjudicaciones de las cuales se desconozca la cuantía de la deuda. 
De la misma manera, no puede proceder a realizar adjudicaciones sobre obligaciones que no sean exigibles. Por lo anterior, si no se ha proferido resolución sanción por no declarar o liquidación oficial de aforo, lo más probable es que la sociedad en trámite de insolvencia no pague suma alguna por concepto de retención en la fuente, si no realizó la presentación de la declaración. Tratándose de las declaraciones ineficaces, los liquidadores de las empresas en insolvencia en algunos casos las han reconocido en el proyecto de graduación y calificación de créditos como obligaciones ciertas. Sin embargo, si el pago de estas no incluye los intereses, por ser un crédito postergado, no se subsana la ineficacia.

También se expuso en el presente trabajo el problema de la injusta autoimposición de la sanción por extemporaneidad por el contribuyente que presentó su declaración de retención en la fuente oportunamente, pero que por no haber realizado el pago oportunamente su declaración se tornó en ineficaz, por cuanto lo que verdaderamente la norma está sancionando no es la presentación extemporánea de la declaración sino el retardo en el pago, el cual es objeto de intereses moratorios.

Finalmente, como al momento de consagrar la ineficacia no se armonizó el Estatuto Tributario con las demás normas, se ha presentado un problema adicional para la administración, consistente en el rechazo de las solicitudes de facilidades de pago por concepto de retenciones en la fuente, pese a que el Artículo 814 E.T. lo permite, por cuanto en presencia de una declaración ineficaz no hay una obligación clara, expresa y exigible.
La solución a los problemas asociados con la consagración de la ineficacia de las declaraciones de retención en la fuente parte de propuestas legislativas que persiguen otorgarle a la administración tributaria todas las facultades para lograr un cobro coactivo efectivo, así como procedimientos para una fiscalización más ágil.

La primera propuesta de solución a la problemática asociada con la consagración de la ineficacia de las declaraciones de retención en la fuente presentadas sin pago total consiste en considerar tales declaraciones como válidas. Para ello, deberá derogarse el Artículo 580-1 del Estatuto Tributario y el parágrafo $5^{\circ}$ del Artículo 1.6.1.13.2.35. del Decreto 2020 del 7 de febrero de 2017, que modificó el Decreto 1625 de 2016 Único reglamentario en materia tributaria. De esa manera, quedarían solucionados el problema de la ausencia de título ejecutivo y la imposibilidad de practicar medidas cautelares.

En lo referente a las dificultades de aplicación de la presente propuesta, tenemos que la implementación de esta implica la modificación del aplicativo SIPAC para que figuren como cobrables las retenciones en la fuente.

De otra parte, teniendo en cuenta que con la modificación propuesta la administración se encontraría facultada para otorgar facilidades de pago por concepto de retenciones en la fuente hasta por un término de cinco (5) años, tenemos que el término es muy largo si se quiere que la administración cuente con un flujo constante de recursos, por lo cual se propuso incluir un parágrafo en el Artículo 814 E.T., en el cual se contemple el pago de las retenciones en la fuente como un requi- 
sito para el otorgamiento de las facilidades, así como el previsto en el numeral $4^{\circ} \mathrm{del} \mathrm{Ar}$ tículo $10^{\circ}$ de la Ley 1116 de 2006 (Régimen de insolvencia empresarial en la República de Colombia), antes de la modificación de la Ley 1429 de 2010, para los acuerdos de reorganización.

También se propuso que la administración realizara una fiscalización oportuna de los contribuyentes omisos en la presentación de las declaraciones de retención en la fuente, mediante la implementación de las siguientes medidas:

1. Un programa de fiscalización de omisos en retención en la fuente, por cuanto los programas han estado enfocados en los omisos e inexactos en el impuesto sobre la renta y en el impuesto al valor agregado IVA.

2. Reducción del término que tienen las Divisiones de Gestión de Fiscalización para adelantar las investigaciones por omisos en retención en la fuente de cinco (5) a tres (3) años.

3. Implementar el procedimiento de la liquidación provisional para la determinación de las retenciones en la fuente. Esta última medida es la más difícil de implementar por cuanto con ella podrían considerarse vulnerados los derechos al debido proceso y el derecho a la igualdad de los contribuyentes.

\section{Referencias}

\section{Jurisprudencia}

Corte Constitucional. Sentencia C-054 de 6 de febrero de 1997. Expediente: D-1384. Recuperada de: http://www.corteconstitucional.gov.co/ relatoria/1997/C-054-97.htm.
Consejo de Estado. Sección Cuarta. Sentencia del 20 de agosto de 2009. Expediente 16038.

\section{Legislación}

Estatuto Tributario PwC. 2 ed. Bogotá: Panamericana Formas e Impresos S.A., 2017.

Henao Carrasquilla, Óscar Eduardo (2013). Código General del Proceso Anotado. 3 ed. Bogotá: Leyer Editores.

Nuevo Código de Procedimiento Administrativo y de lo Contencioso Administrativo - Ley 1437 de 2011. En: Código Contencioso Administrativo Decreto 01 de 1984. 25ª ed. Bogotá: 2011.

Régimen concursal y de insolvencia colombiano. Superintendencia de Sociedades. 2 ed. Bogotá: Imprenta Nacional de Colombia, 2014.

Ley 58 de 17 de diciembre de 2003, General Tributaria. Recuperada el 22 de abril de 2017 de https://www.boe.es/buscar/act.php?id=BOE-A-2003$23186 \&$ tn $=1 \& \mathrm{p}=20161203 \# \mathrm{a} 37$

\section{Conceptos y autos de la Superintendencia de Sociedades}

DIAN. Concepto No. 40423 del 14 de julio de 2003.

DIAN. Concepto No. 000496 del 31 de mayo de 2016.

Superintendencia de Sociedades. Oficio No. 220005655 del 27 de enero de 2014.

Superintentencia de Sociedades. Acta de la audiencia de resolución de objeciones llevada a cabo el 30 de octubre de 2015 dentro del trámite de liquidación judicial de la sociedad Sismografía y Petróleos de Colombia S.A.S. Expediente: 39.695.

\section{Doctrina}

Coordinación Escuela de Impuestos y Aduanas Nacionales (2016). Proceso de administración de cartera. Módulo de cobro coactivo.

Devis Echandía, Hernando (1964). "Tratado de Derecho procesal civil. Bogotá: Editorial Temis. Tomo IV (pp. 514), en Código General del Proceso anotado (2013). Tercera edición: Leyer Editores (pp. 685-686).

García Celis, Diana Victoria (2015). Curso de medidas cautelares. U.A.E. DIAN. 2011. Actualizado por Martínez Rivera, Alejandro y Penagos Correa, Julián. 
García Escobar, Gabriel (2014). "El tratamiento de los créditos concursales y el 1 principio par conditio creditorum", en Revista Internacional de Doctrina y Jurisprudencia. Disponible en https://w3.ual.es/ revistas/...pdfs/2014-03/articulos_el-tratamiento-delos-creditos.pdf.

García, Bibiana (2017). "Las liquidaciones provisionales”, en Piza Rodríguez, Julio (coordinador). Análisis crítico de la reforma tributaria Ley 1819 de 2016. Serie reformas tributarias -SRT (pp.519-533). Bogotá D.C.: Universidad Externado de Colombia. 2017.

González Parra, Olga Lucía (2011). La fiscalización y determinación tributaria: un análisis desde la perspectiva jurídica y de gestión pública. Tesis de Maestría en Derecho con énfasis en Tributación. Bogotá D.C.: Universidad Externado de Colombia.

Jara Céspedes, Luz Helena y Forero Cuevas, Duván Ernesto (2007). Propuesta implementación programa de fiscalización para las declaraciones informativas individual y consolidada de precios de transferen- cias. Tesis de Maestría en Derecho con énfasis en Tributación. Bogotá D.C.: Universidad Externado de Colombia.

Piza Rodríguez, Julio Roberto y González Parra, Olga Lucía (2010). "Fiscalización y determinación tributaria", en Julio Roberto Piza Rodríguez (editor), Curso de Derecho Tributario, procedimiento y régimen sancionatorio (pp. 621-688). Bogotá D.C.: Universidad Externado de Colombia.

Rico, Cecilia (2011). "Las facilidades o acuerdos de pago: oportunidad, condiciones y aplicación", en $L a$ cobranza administrativa como mecanismo efectivo de incremento del recaudo (Conferencia Técnica del CIAT. Lisboa, Portugal, 2011). Recuperado el 4 de diciembre de 2017 de http://biblioteca.ciat.org/opac/.

Sánchez Uribe, Álvaro (2012). Identificación de vacíos jurídicos en la formación de actos de procedimiento tributario. Tesis de Maestría en Derecho con énfasis en Tributación. Bogotá D.C.: Universidad Externado de Colombia. 